\title{
Dual Glycolate Oxidase/Lactate Dehydrogenase A Inhibitors for Primary Hyperoxaluria
}

Jinyue Ding ${ }^{1, *}$, Rajesh Gumpena ${ }^{2}$, Marc-Olivier Boily ${ }^{1}$, Alexandre Caron ${ }^{1}$, Oliver Chong ${ }^{1}$, Jennifer H. Cox ${ }^{1}, V^{2}$ alerie Dumais $^{1}$, Samuel Gaudreault ${ }^{1}$, Aaron H. Graff ${ }^{2}$, Andrew King ${ }^{1}$, John Knight ${ }^{3}$, Renata Oballa ${ }^{1}$, Jayakumar Surendradoss ${ }^{1}$, TimTang $^{1}$, Joyce $\mathrm{Wu}^{1}, \mathrm{~W}$. Todd Lowther ${ }^{2, *}$, David A. Powell ${ }^{1}$

\footnotetext{
${ }^{1}$ Chinook Therapeutics, 210-887 Great Northern Way, Vancouver, BC, V5T 4T5, Canada and 1600 Fairview Ave E Suite \#100, Seattle WA 98102, United States of America

${ }^{2}$ Center for Structural Biology, Department of Biochemistry, Wake Forest School of Medicine, Medical Center Blvd., WinstonSalem, NC, 27157, United States of America

${ }^{3}$ Department of Urology, University of Alabama at Birmingham, $72020^{\text {th }}$ Street South, Birmingham, AL, 35294, United States of America
}

\section{Supporting Information}

\section{Table of Contents}

I. General Information .S1

II. Preparation of compounds 7 to 17

.S1-10

III. Protein production and purification. S10-11

IV. X-ray Crystallography. S11-12

V. Biochemical and hepatocyte assays. S12-13

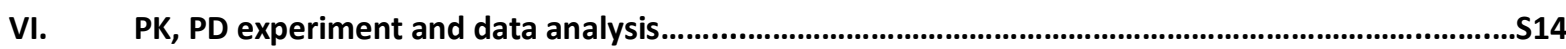

VII. References.

VIII. ${ }^{1} \mathrm{H}$ NMR spectra S16-21

\section{General Information:}

The starting materials used for the synthesis were prepared according to known literature procedures or obtained from commercial sources, such as, but not limited to, Sigma-Aldrich, Fluka, Acros Organics, Alfa Aesar, VWR Scientific, and the like. Nuclear Magnetic Resonance (NMR) analysis was conducted using a $400 \mathrm{MHz}$ spectrometer with an appropriate deuterated solvent. Chemical shift $(\delta)$ is expressed in units of parts per million (ppm). LCMS analysis was conducted using a Shimadzu LCMS-2020 with a Ascentis Express C18 $2.7 \mu \mathrm{M}, 3.0 \times 50 \mathrm{~mm}$ column, eluting with 95:5 to 0:100 $\mathrm{H}_{2} \mathrm{O}: \mathrm{MeCN}+0.05 \%$ trifluoroacetic acid at a flow rate of $1.5 \mathrm{~mL} / \mathrm{min}$ over $3.0 \mathrm{minutes}$. The QDA MS detector was set up to scan under both positive and negative mode ions ranging from 100-1200 Daltons. General methods for the preparation of compounds can be modified by the use of appropriate reagents and conditions for the introduction of the various moieties found in the structures as provided herein.

Preparation of 2-(3-(3-((4-carboxy-1H-1,2,3-triazol-5-yl)thio)phenyl)-5-(cyclopropylmethyl)-4-(3-fluoro-4sulfamoylbenzyl)-1H-pyrazol-1-yl)thiazole-4-carboxylic acid (Compound 7) 


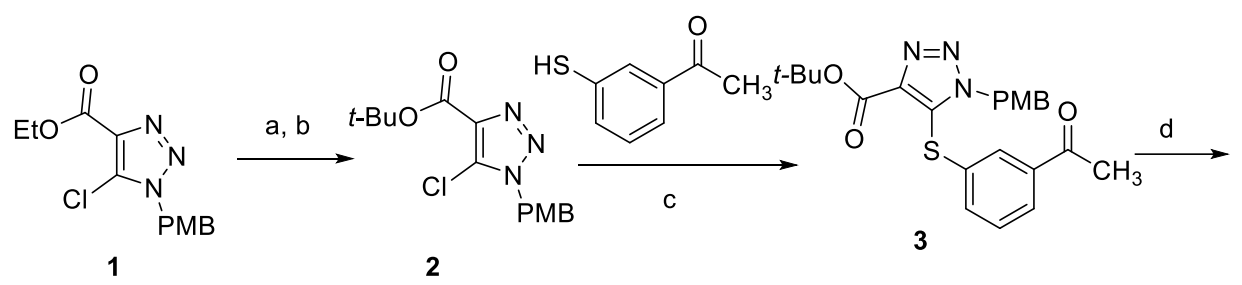<smiles>CCOC(=O)c1csc(N)n1</smiles>

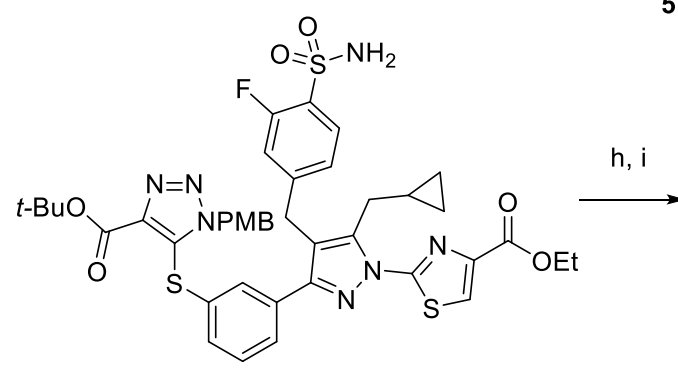

6

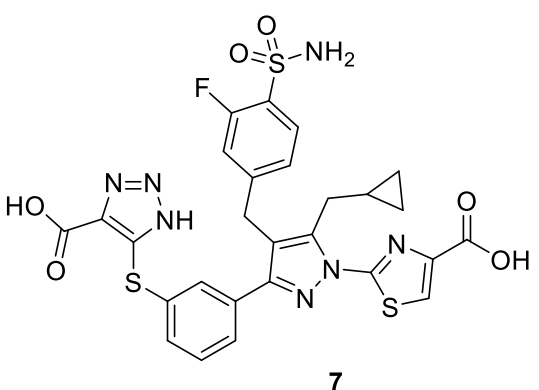

7

Step a: Preparation of 5-chloro-1-(4-methoxybenzyl)-1H-1,2,3-triazole-4-carboxylic acid

Into a $1 \mathrm{~L}$ round-bottom flask was placed ethyl 5-chloro-1-(4-methoxybenzyl)-1H-1,2,3-triazole-4carboxylate $(20.0 \mathrm{~g}, 67.6 \mathrm{mmol}, 1.0$ equiv), THF $(200 \mathrm{~mL})$, solid LiOH (16.2 g, $676 \mathrm{mmol}, 10$ equiv) and water (400 $\mathrm{mL}$ ). The resulting solution was stirred at $25{ }^{\circ} \mathrm{C}$ for $4 \mathrm{~h}$. The resulting mixture was concentrated under reduced pressure and the residue was acidified to $\mathrm{pH}=2$ with $1 \mathrm{M}$ aqueous $\mathrm{HCl}$ solution. The precipitated solids were collected by filtration and washed with water $(2 \times 10 \mathrm{~mL})$. The title compound, 5-chloro-1-(4-methoxybenzyl)-1H-1,2,3triazole-4-carboxylic acid, was obtained as a white solid ( $12 \mathrm{~g}, 66 \%$ yield).

Step b: Preparation of tert-butyl 5-chloro-1-(4-methoxybenzyl)-1H-1,2,3-triazole-4-carboxylate

Into a $500 \mathrm{~mL}$ round-bottom flask equipped with a magnetic stir bar and under a nitrogen atmosphere was placed 5-chloro-1-[(4-methoxyphenyl)methyl]-1,2,3-triazole-4-carboxylic acid (10.0 g, 37.3 mmol, 1.0 equiv), Boc $2 \mathrm{O}$ (16.3 g, 74.7 mmol, 2.0 equiv), DMAP (0.90 g, 7.5 mmol, 0.2 equiv), EtN(iPr) 2 (15.3 mL, 112 mmol, 3.0 equiv) and $\mathrm{CH}_{2} \mathrm{Cl}_{2}(200 \mathrm{~mL})$. The resulting solution was stirred at $25^{\circ} \mathrm{C}$ for $3 \mathrm{~h}$. The reaction was then quenched by the addition of $100 \mathrm{~mL}$ of water. The resulting solution was poured into a separatory funnel and extracted with ethyl acetate (3 $\times 200 \mathrm{~mL}$ ). The combined organic layers were concentrated, and the residue was applied onto a silica gel column. The column was eluted with ethyl acetate/petroleum ether (1:10). The fractions containing tert-butyl 5-chloro-1-(4methoxybenzyl)-1H-1,2,3-triazole-4-carboxylate were isolated, concentrated and dried under vacuum to afford a yellow solid ( $10 \mathrm{~g}, 83 \%$ yield).

Step c: Preparation of tert-butyl 5-(3-acetylphenyl)sulfanyl-3-[(4-methoxyphenyl)methyl]triazole-4carboxylate 
Into a $100 \mathrm{~mL}$ round bottom flask was added tert-butyl 5-chloro-1-[(4-methoxyphenyl)methyl]triazole-4carboxylate (1.1 equiv, $2.3 \mathrm{~g}, 7.2 \mathrm{mmol}$ ), 1-(3-sulfanylphenyl)ethanone (1.0 equiv, $1.0 \mathrm{~g}, 6.6 \mathrm{mmol}$ ), potassium carbonate ( 2.5 equiv, $2.3 \mathrm{~g}, 16 \mathrm{mmol}$ ) and DMF ( $22 \mathrm{~mL}$ ). The mixture was stirred at $130^{\circ} \mathrm{C}$ for 18 hours. The reaction was filtered and loaded directly on a $25 \mathrm{~g}$ normal phase pre-cartridge. Purification by column chromatography through silica gel [330 g gold Teledyne silica gel cartridge] on a Teledyne ISCO Rf system, eluting with 95:5 to 50:50 hexanes:EtOAc as a gradient over 35 minutes, collecting all peaks. The desired product containing fractions were concentrated and dried under vacuum to afford a clear oil ( $2.5 \mathrm{~g}, 87 \%$ yield).

Step d: Preparation of tert-butyl 5-[3-(4-cyclopropyl-3-oxo-butanoyl)phenyl]sulfanyl-1-[(4methoxyphenyl)methyl]triazole-4-carboxylate

To a mixture of tert-butyl 5-(3-acetylphenyl)sulfanyl-3-[(4-methoxyphenyl)methyl]triazole-4-carboxylate (1.0 equiv, $2.0 \mathrm{~g}, 4.5 \mathrm{mmol}$ ), 1-(benzotriazol-1-yl)-2-cyclopropyl-ethanone (1.5 equiv, $1.4 \mathrm{~g}, 6.8 \mathrm{mmol}$ ) and magnesium bromide ethyl etherate ( 2.5 equiv, $2.9 \mathrm{~g}, 11 \mathrm{mmol}$ ) in $\mathrm{CH}_{2} \mathrm{Cl}_{2}(25 \mathrm{~mL})$, cooled over an ice bath was added $\operatorname{EtN}(i \operatorname{Pr})_{2}(4.6 \mathrm{~g}, 36 \mathrm{mmol}, 6.3 \mathrm{~mL})$ dropwise over 10 minutes using an addition funnel. After the addition was complete, the ice bath was removed and the reaction was stirred at $23^{\circ} \mathrm{C}$ for 18 hours. An additional amount of $\mathrm{CH}_{2} \mathrm{Cl}_{2}(19 \mathrm{~mL})$ was added to make stirring more effective. After this time, the reaction mixture was acidified with $1 \mathrm{M}$ aqueous $\mathrm{HCl}(48 \mathrm{~mL})$ and stirred for 5 minutes. The layers were partitioned and the aqueous was back extracted with $\mathrm{CH}_{2} \mathrm{Cl}_{2}(30 \mathrm{~mL})$. The combined organic extracts were washed with water $(20 \mathrm{~mL})$, dried over $\mathrm{MgSO}_{4}$, filtered and then concentrated under vacuum to an oil. This material was applied to a silica gel pre-cartridge and then purified by column chromatography using a $120 \mathrm{~g}$ silica Teledyne ISCO cartridge eluting with a 0:100 to 25:75 EtOAc:hexanes as a gradient. The fractions from the first peak were combined and concentrated under vacuum, resulting in the title product as a light yellow oil ( $1.2 \mathrm{~g}, 51 \%$ yield).

Step e: Preparation of tert-butyl 5-[3-[4-cyclopropyl-2-[(3-fluoro-4-sulfamoyl-phenyl)methyl]-3-oxobutanoyl]phenyl]sulfanyl-1-[(4-methoxyphenyl)methyl]triazole-4-carboxylate

Into a $200 \mathrm{~mL}$ round-bottom flask equipped with a magnetic stir bar and under $\mathrm{N}_{2}$ was added tert-butyl 5[3-(4-cyclopropyl-3-oxo-butanoyl)phenyl]sulfanyl-1-[(4-methoxyphenyl)methyl]triazole-4-carboxylate (1.0 equiv, $4.3 \mathrm{~g}, 8.3 \mathrm{mmol}$ ) and DMSO ( $25 \mathrm{~mL})$. The solution was treated with cesium carbonate (1.2 equiv, $3.3 \mathrm{~g}, 9.9 \mathrm{mmol})$ and stirred for 10 minutes. 4-(Bromomethyl)-2-fluorobenzenesulfonamide (1.2 equiv, $2.7 \mathrm{~g}, 9.9 \mathrm{mmol}$ ) was then added. The mixture was stirred at room temperature for $2 \mathrm{~h}$. LCMS analysis after this time reveals product formation. The reaction mixture was quenched with $1 \mathrm{M}$ aqueous $\mathrm{HCl}$ solution $(50 \mathrm{~mL})$ and water $(100 \mathrm{~mL})$. The mixture was poured into a $250 \mathrm{~mL}$ separatory funnel and extracted with $\mathrm{CH}_{2} \mathrm{Cl}_{2}(3 \times 50 \mathrm{~mL})$. The combined organic layers were washed with brine $(50 \mathrm{~mL})$, dried over $\mathrm{MgSO}_{4}$, filtered and concentrated under reduced pressure. The residue was loaded onto a $20 \mathrm{~g}$ silica gel pre-cartridge and dried. Purification by column chromatography through silica gel on the ISCO Rf [120 g GOLD], eluting with 95:5 to 10:90 hexanes:EtOAc as a gradient over 30 minutes, collect all peaks. The product containing fractions were combined, concentrated and further dried under vacuum, yielding the title product as a clear oil $(1.3 \mathrm{~g}, 78 \%$ yield).

Step f: Preparation of tert-butyl 5-[3-[5-(cyclopropylmethyl)-4-[(3-fluoro-4-sulfamoyl-phenyl)methyl]-1Hpyrazol-3-yl]phenyl]sulfanyl-1-[(4-methoxyphenyl)methyl]triazole-4-carboxylate

Into a $100 \mathrm{~mL}$ round-bottom flask equipped with a magnetic stir bar and under $\mathrm{N}_{2}$ was added tert-butyl 5[3-[4-cyclopropyl-2-[(3-fluoro-4-sulfamoyl-phenyl)methyl]-3-oxo-butanoyl]phenyl]sulfanyl-1-[(4methoxyphenyl)methyl]triazole-4-carboxylate (1.0 equiv, $1.3 \mathrm{~g}, 1.8 \mathrm{mmol}$ ), hydrazine-monohydrate (2.0 equiv, 180 $\mu \mathrm{L}, 3.7 \mathrm{mmol}$ ) and ethanol $(6.1 \mathrm{~mL})$. The solution was heated to $70^{\circ} \mathrm{C}$ in an oil bath for $2 \mathrm{~h}$. LCMS after this time reveals product formation. The reaction mixture was cooled to room temperature and concentrated under reduced 
pressure. The residue was further dried via co-evaporation with EtOH to drive off water and excess hydrazine. The resulting crude oil was dried under vacuum for $18 \mathrm{~h}$ overnight to afford the title product as a yellow foam $(1.2 \mathrm{~g}$, $93 \%$ yield), which was used in next step without further purification.

Step g: Preparation of ethyl 2-[3-[3-[5-tert-butoxycarbonyl-3-[(4-methoxyphenyl)methyl]triazol-4yl]sulfanylphenyl]-5-(cyclopropylmethyl)-4-[(3-fluoro-4-sulfamoyl-phenyl)methyl]pyrazol-1-yl]thiazole-4carboxylate

Into a $20 \mathrm{~mL}$ vial equipped with a magnetic stir bar and under $\mathrm{N}_{2}$ was added tert-butyl 5-[3-[5(cyclopropylmethyl)-4-[(3-fluoro-4-sulfamoyl-phenyl)methyl]-1H-pyrazol-3-yl]phenyl]sulfanyl-1-[(4methoxyphenyl)methyl]triazole-4-carboxylate (1.0 equiv, $400 \mathrm{mg}, 0.6 \mathrm{mmol}$ ), ethyl 2-fluorothiazole-4-carboxylate ( 1.2 equiv, $120 \mathrm{mg}, 0.70 \mathrm{mmol}$ ), sodium tert-pentoxide ( 2.5 equiv, $160 \mathrm{mg}, 1.4 \mathrm{mmol}$ ) and DMF ( $2.3 \mathrm{~mL}$ ). The mixture was stirred at room temperature for 1 hour. LCMS analysis indicated formation of desired product. The reaction was quenched by formic acid $(0.1 \mathrm{~mL})$, loaded directly onto a $20 \mathrm{~g}$ silica gel pre-cartridge and dried under vacuum. Purification by column chromatography through silica gel [ $80 \mathrm{~g}$ gold Teledyne silica gel cartridge] on a Teledyne ISCO Rf system, eluting with 100:0 to 0:100 hexanes:EtOAc as a gradient over 45 minutes, collecting all peaks. The desired product containing fractions were concentrated and dried under vacuum to afford a clear oil (104 mg, 21\% yield).

Step h: Preparation of 2-(5-(cyclopropylmethyl)-3-(3-((4-(ethoxycarbonyl)-1H-1,2,3-triazol-5yl)thio)phenyl)-4-(3-fluoro-4-sulfamoylbenzyl)-1H-pyrazol-1-yl)thiazole-4-carboxylic acid

Into a $4 \mathrm{~mL}$ reaction vial was added ethyl 2-[3-[3-[5-tert-butoxycarbonyl-3-[(4methoxyphenyl)methyl]triazol-4-yl]sulfanylphenyl]-5-(cyclopropylmethyl)-4-[(3-fluoro-4-sulfamoyl-

phenyl)methyl]pyrazol-1-yl]thiazole-4-carboxylate (1.0 equiv, $100 \mathrm{mg}, 0.1 \mathrm{mmol}$ ), triethylsilane (14 equiv, $250 \mu \mathrm{L}$, $1.6 \mathrm{mmol}$ ) and $\mathrm{CH}_{2} \mathrm{Cl}_{2}(250 \mu \mathrm{L})$. The mixture was stirred at $23^{\circ} \mathrm{C}$ for $5 \mathrm{~min}$. Trifluoroacetic acid (57 equiv, $500 \mu \mathrm{L}, 7$ $\mathrm{mmol}$ ) was added slowly. The mixture was stirred at $23^{\circ} \mathrm{C}$ and monitored by LCMS. Upon completion of reaction, the reaction was concentrated. The resulting crude mixture was dissolved in methanol and injected onto a preparative HPLC (ACCQPrep HP125 UV). Purification by a reverse phase prep HPLC column chromatography (C18 column dimensions: $20 \mathrm{~mm} \times 150 \mathrm{~mm}, 5 \mu \mathrm{m}$ ), eluting with $90: 10$ to 0:100 water:MeCN $+0.1 \%$ formic acid as a gradient over 35 minutes, collecting all peaks. The desired product containing fractions were concentrated and lyophilized overnight to yield the title product as a white powder (15 mg, 18\% yield).

Step i: Preparation of 2-(3-(3-((4-carboxy-1H-1,2,3-triazol-5-yl)thio)phenyl)-5-(cyclopropylmethyl)-4-(3fluoro-4-sulfamoylbenzyl)-1H-pyrazol-1-yl)thiazole-4-carboxylic acid

In a $4 \mathrm{~mL}$ reaction vial was added 2-(5-(cyclopropylmethyl)-3-(3-((4-(ethoxycarbonyl)-1H-1,2,3-triazol-5yl)thio)phenyl)-4-(3-fluoro-4-sulfamoylbenzyl)-1H-pyrazol-1-yl)thiazole-4-carboxylic acid (1.0 equiv, $15 \mathrm{mg}$ ) and $1 \mathrm{M}$ aqueous LiOH/THF/MeOH (10 equiv, $660 \mu \mathrm{L}, \mathrm{v} / \mathrm{v} / \mathrm{v}, 1 / 1 / 1$ ) and stirred at $23^{\circ} \mathrm{C}$ for 18 hours. LCMS analysis indicated completion of hydrolysis. The reaction was quenched dropwise with concentration formic acid until the pH was $\sim 2$. The mixture was concentrated and injected directly to prep HPLC (ACCQPrep HP125 UV). Purification by a reverse phase preparative HPLC column chromatography (C18 column dimensions: $20 \mathrm{~mm} \times 150 \mathrm{~mm}, 5 \mu \mathrm{m}$ ), eluting with 90:10 to 0:100 water:MeCN $+0.1 \%$ formic acid as a gradient over 25 minutes, collecting all peaks. The desired product containing fractions were concentrated and lyophilized overnight to yield the title product as a white powder ( $8.2 \mathrm{mg}, 45 \%$ yield). ${ }^{1} \mathrm{H}$ NMR $\left(400 \mathrm{MHz}, d_{6}\right.$-DMSO) $\delta 8.29(\mathrm{~s}, 1 \mathrm{H}), 7.66(\mathrm{t}, J=8.0 \mathrm{~Hz}, 1 \mathrm{H}), 7.62(\mathrm{~s}, 1 \mathrm{H}), 7.56(\mathrm{~s}$, $2 \mathrm{H}), 7.45(\mathrm{t}, J=7.0 \mathrm{~Hz}, 1 \mathrm{H}), 7.39(\mathrm{~s}, 1 \mathrm{H}), 7.09(\mathrm{~d}, J=11.2 \mathrm{~Hz}, 1 \mathrm{H}), 6.99(\mathrm{~d}, J=8.2 \mathrm{~Hz}, 1 \mathrm{H}), 4.11(\mathrm{~s}, 2 \mathrm{H}), 2.41(\mathrm{~d}, J=6.9$ $\mathrm{Hz}, 2 \mathrm{H}), 0.92-0.88(\mathrm{~m}, 1 \mathrm{H}), 0.41-0.30(\mathrm{~m}, 2 \mathrm{H}), 0.19-0.09(\mathrm{~m}, 2 \mathrm{H})$. LC-MS (ESI) $\mathrm{m} / \mathrm{z} 656(\mathrm{M}+\mathrm{H})^{+} ;\left[(\mathrm{M}+\mathrm{H})^{+}\right.$calculated for $\left.\mathrm{C}_{27} \mathrm{H}_{22} \mathrm{FN}_{7} \mathrm{O}_{6} \mathrm{~S}_{3}, 655.69\right]$. 
Preparation of 2-(3-(3-((4-carboxy-1H-1,2,3-triazol-5-yl)oxy)-4-fluorophenyl)-5-(cyclopropylmethyl)-4-(3-fluoro-4sulfamoylbenzyl)-1H-pyrazol-1-yl)thiazole-4-carboxylic acid (Compound 11)
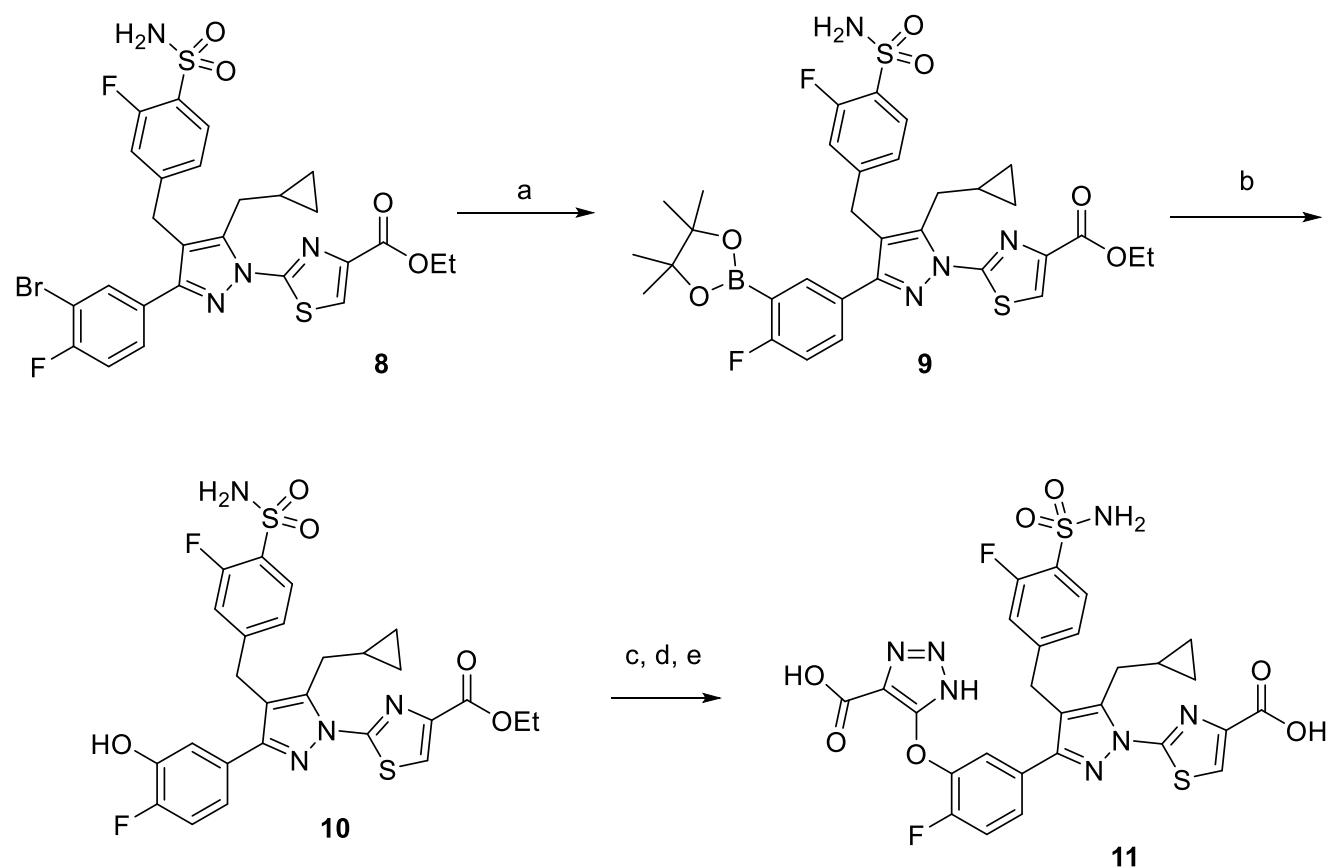

Step a: Preparation of ethyl 2-(5-(cyclopropylmethyl)-3-(4-fluoro-3-(4,4,5,5-tetramethyl-1,3,2dioxaborolan-2-yl)phenyl)-4-(3-fluoro-4-sulfamoylbenzyl)-1H-pyrazol-1-yl)thiazole-4-carboxylate

To a degassed solution of ethyl 2-[3-(3-bromo-4-fluoro-phenyl)-5-(cyclopropylmethyl)-4-[(3-fluoro-4sulfamoyl-phenyl)methyl]pyrazol-1-yl]thiazole-4-carboxylate (1.0 equiv, $700 \mathrm{mg}, 1.1 \mathrm{mmol}$, synthesized by following published procedures (WO 2016/109559)), bis(pinacolato)diboron (2.0 equiv, $560 \mathrm{mg}, 2.2 \mathrm{mmol}$ ) and potassium acetate (3.0 equiv, $320 \mathrm{mg}, \quad 3.3 \mathrm{mmol})$ in 1,4-dioxane $(3.1 \mathrm{~mL})$ was added [1,1'bis(diphenylphosphino)ferrocene]dichloropalladium(II), complex with dichloromethane (0.1 equiv, $90 \mathrm{mg}, 0.1$ $\mathrm{mmol})$. The reaction was heated to $100{ }^{\circ} \mathrm{C}$ overnight. This mixture was diluted with EtOAc $(5 \mathrm{~mL})$, filtered and concentrated under vacuum. This residue was purified by column chromatography through silica gel $[40 \mathrm{~g}$ gold Teledyne silica gel cartridge] on a Teledyne ISCO Rf system, eluting with 100:0 to 0:100 hexanes:EtOAc as a gradient over 25 minutes, collecting all peaks. The fractions from the major peak were combined, concentrated under vacuum, and further dried under high vacuum overnight, yielding the title product as a while solid ( $342 \mathrm{mg}, 46 \%$ yield).

Step b: Preparation of ethyl 2-(5-(cyclopropylmethyl)-3-(4-fluoro-3-hydroxyphenyl)-4-(3-fluoro-4sulfamoylbenzyl)-1H-pyrazol-1-yl)thiazole-4-carboxylate

Into a round bottom flask was added ethyl 2-[5-(cyclopropylmethyl)-4-[(3-fluoro-4-sulfamoylphenyl)methyl]-3-[4-fluoro-3-(4,4,5,5-tetramethyl-1,3,2-dioxaborolan-2-yl)phenyl]pyrazol-1-yl]thiazole-4-

carboxylate (1.0 equiv, $340 \mathrm{mg}, 0.5 \mathrm{mmol}$ ), [5-[5-(cyclopropylmethyl)-1-(4-ethoxycarbonylthiazol-2-yl)-4-[(3-fluoro4-sulfamoyl-phenyl)methyl]pyrazol-3-yl]-2-fluoro-phenyl]boronic acid (1.0 equiv, $300 \mathrm{mg}, 0.5 \mathrm{mmol}$ ), urea hydrogen peroxide adduct (4.0 equiv, $190 \mathrm{mg}, 2.0 \mathrm{mmol}$ ) and methanol $(1.7 \mathrm{~mL})$. The mixture was stirred at $23{ }^{\circ} \mathrm{C}$ and monitored by LCMS. After stirring for 2 hours, LCMS analysis indicated completion of reaction by LCMS. The reaction was quenched by adding $10 \%$ aqueous sodium thiosulfate. The mixture was loaded directly on reverse phase $\mathrm{C} 18$ pre-cartridge and dried. Purification by a reverse phase column chromatography through silica gel $[80 \mathrm{~g}$ gold 
C18 Teledyne silica gel cartridge] on a Teledyne ISCO Rf system, eluting with 95:5 to 0:100 water: $\mathrm{CH}_{3} \mathrm{CN}+$ $0.1 \%$ formic acid as a gradient over 30 minutes, collecting all peaks. The product-containing fractions were combined, concentrated under vacuum and further dried under high vacuum overnight, yielding the title product as a while solid ( $237 \mathrm{mg}, 82 \%$ yield).

Step c: Preparation of ethyl 2-[3-[3-[5-tert-butoxycarbonyl-3-[(4-methoxyphenyl)methyl]triazol-4-yl]oxy-4fluoro-phenyl]-5-(cyclopropylmethyl)-4-[(3-fluoro-4-sulfamoylphenyl)methyl]pyrazol-1-yl]thiazole-4-carboxylate

Into a $4 \mathrm{~mL}$ reaction vial was added tert-butyl 5-chloro-1-[(4-methoxyphenyl)methyl]triazole-4-carboxylate (0.8 equiv, $0.14 \mathrm{~g}, 0.42 \mathrm{mmol}$ ), ethyl 2-[5-(cyclopropylmethyl)-3-(4-fluoro-3-hydroxy-phenyl)-4-[(3-fluoro-4sulfamoyl-phenyl)methyl]pyrazol-1-yl]thiazole-4-carboxylate ( 1.0 equiv, $0.3 \mathrm{~g}, 0.5 \mathrm{mmol}$ ), potassium carbonate $(3.0$ equiv, $220 \mathrm{mg}, 1.6 \mathrm{mmol}$ ) and DMF $(2.6 \mathrm{~mL})$. The mixture was stirred at $110^{\circ} \mathrm{C}$ for 2 hours. LCMS analysis indicated product formation. The reaction was filtered and loaded directly onto a $20 \mathrm{~g}$ silica gel pre-cartridge and dried under vacuum. The mixture was purified by column chromatography through silica gel $[40 \mathrm{~g}$ gold Teledyne silica gel cartridge] on a Teledyne ISCO Rf system, eluting with 95:5 to 0:100 hexanes:EtOAc as a gradient over 25 minutes, collecting all peaks. The desired product containing fractions were concentrated and dried under vacuum to afford a clear oil ( $88 \mathrm{mg}, 19 \%$ yield).

Step d: Preparation of 4-[5-[5-(cyclopropylmethyl)-1-(4-ethoxycarbonylthiazol-2-yl)-4-[(3-fluoro-4sulfamoyl-phenyl)methyl]pyrazol-3-yl]-2-fluoro-phenoxy]-1H-triazole-5- carboxylic acid

Into a $4 \mathrm{~mL}$ reaction vial was added ethyl 2-[3-[3-[5-tert-butoxycarbonyl-3-[(4methoxyphenyl)methyl]triazol-4-yl]oxy-4-fluoro-phenyl]-5-(cyclopropylmethyl)-4-[(3-fluoro-4-sulfamoyl-

phenyl)methyl]pyrazol-1-yl]thiazole-4-carboxylate (1.0 equiv, $88 \mathrm{mg}, 0.10 \mathrm{mmol}$ ), triethylsilane (12 equiv, $0.20 \mathrm{~mL}$, $1.3 \mathrm{mmol}$ ) and $\mathrm{CH}_{2} \mathrm{Cl}_{2}\left(0.2 \mathrm{~mL}\right.$ ). The mixture was stirred at $23^{\circ} \mathrm{C}$ for $5 \mathrm{~min}$. Trifluoroacetic acid (52 equiv, $0.40 \mathrm{~mL}$, $5.3 \mathrm{mmol}$ ) was added dropwise. The mixture was stirred at $40^{\circ} \mathrm{C}$ and monitored by LCMS. After stirring at $40{ }^{\circ} \mathrm{C}$ for 4 hours, LCMS analysis indicated completion of reaction. The reaction was concentrated to remove most of trifluoroacetic acid. The resulting crude oil was injected directly onto a preparative HPLC (ACCQPrep HP125 UV). Purification by a reverse phase prep HPLC column chromatography (C18 column dimensions: $20 \mathrm{~mm} \times 150 \mathrm{~mm}, 5$ $\mu \mathrm{m})$, eluting with 90:10 to 0:100 water:MeCN $+0.1 \%$ formic acid as a gradient over 35 minutes, collecting all peaks. The desired product containing fractions were concentrated and lyophilized overnight to yield the title product as a white powder ( $26 \mathrm{mg}, 37 \%$ yield).

Step e: Preparation of 2-(3-(3-((4-carboxy-1H-1,2,3-triazol-5-yl)oxy)-4-fluorophenyl)-5(cyclopropylmethyl)-4-(3-fluoro-4-sulfamoylbenzyl)-1H-pyrazol-1-yl)thiazole-4-carboxylic acid

Into a $4 \mathrm{~mL}$ reaction vial was added 4-[5-[5-(cyclopropylmethyl)-1-(4-ethoxycarbonylthiazol-2-yl)-4-[(3fluoro-4-sulfamoyl-phenyl)methyl]pyrazol-3-yl]-2-fluoro-phenoxy]-1H-triazole-5-carboxylic acid (1.0 equiv, $26 \mathrm{mg}$, $0.038 \mathrm{mmol}), 1 \mathrm{M}$ aqueous LiOH ( 6.0 equiv, $0.23 \mathrm{~mL}, 0.23 \mathrm{mmol}), \operatorname{THF}(0.2 \mathrm{~mL}$ ) and methanol $(0.2 \mathrm{~mL})$. The mixture was stirred at $23^{\circ} \mathrm{C}$ for 18 hours. LCMS analysis indicated completion of hydrolysis. The reaction was quenched with formic acid until the $\mathrm{pH}$ was $\sim 2$. The mixture was concentrated and injected directly to prep HPLC (ACCQPrep HP125 UV). Purification by a reverse phase prep HPLC column (C18 column dimensions: $20 \mathrm{~mm} \times 150 \mathrm{~mm}, 5 \mu \mathrm{m}$ ), eluting with 90:10 to 0:100 water:MeCN $+0.1 \%$ formic acid as a gradient over 25 minutes, collecting all peaks. The desired product containing fractions were concentrated and lyophilized overnight to yield the title product as a white powder (13 mg, 52\% yield). ${ }^{1} \mathrm{H}$ NMR (400 MHz, $d_{6}$-DMSO) $\delta 8.30(\mathrm{~s}, 1 \mathrm{H}), 7.64(\mathrm{t}, J=7.9 \mathrm{~Hz}, 2 \mathrm{H}), 7.61(\mathrm{br} \mathrm{s}, 1 \mathrm{H}), 7.51$ $-7.42(\mathrm{~m}, 1 \mathrm{H}), 7.40(\mathrm{~s}, 1 \mathrm{H}), 7.39-7.32(\mathrm{~m}, 1 \mathrm{H}), 7.09(\mathrm{~d}, J=11.3 \mathrm{~Hz}, 1 \mathrm{H}), 6.99(\mathrm{~d}, J=8.4 \mathrm{~Hz}, 1 \mathrm{H}), 4.11(\mathrm{~s}, 2 \mathrm{H}), 3.14(\mathrm{~d}$, $J=6.9 \mathrm{~Hz}, 2 \mathrm{H}), 1.18-1.04(\mathrm{~m}, 1 \mathrm{H}), 0.40-0.30(\mathrm{~m}, 2 \mathrm{H}), 0.25-0.15(\mathrm{~m}, 2 \mathrm{H})$. LC-MS (ESI) $\mathrm{m} / \mathrm{z} 658(\mathrm{M}+\mathrm{H})^{+}$; [(M+H) ${ }^{+}$ calculated for $\left.\mathrm{C}_{27} \mathrm{H}_{21} \mathrm{~F}_{2} \mathrm{~N}_{7} \mathrm{O}_{7} \mathrm{~S}_{2}, 657.62\right]$. 


\section{Preparation of 2-[3-[3-[3-[(5-carboxy-1H-triazol-4-yl)oxy]phenyl]-4-fluoro-phenyl]-5-(cyclopropylmethyl)-4-[(3- fluoro-4-sulfamoyl-phenyl)methyl]pyrazol-1-yl]thiazole-4-carboxylic acid (Compound 14)}

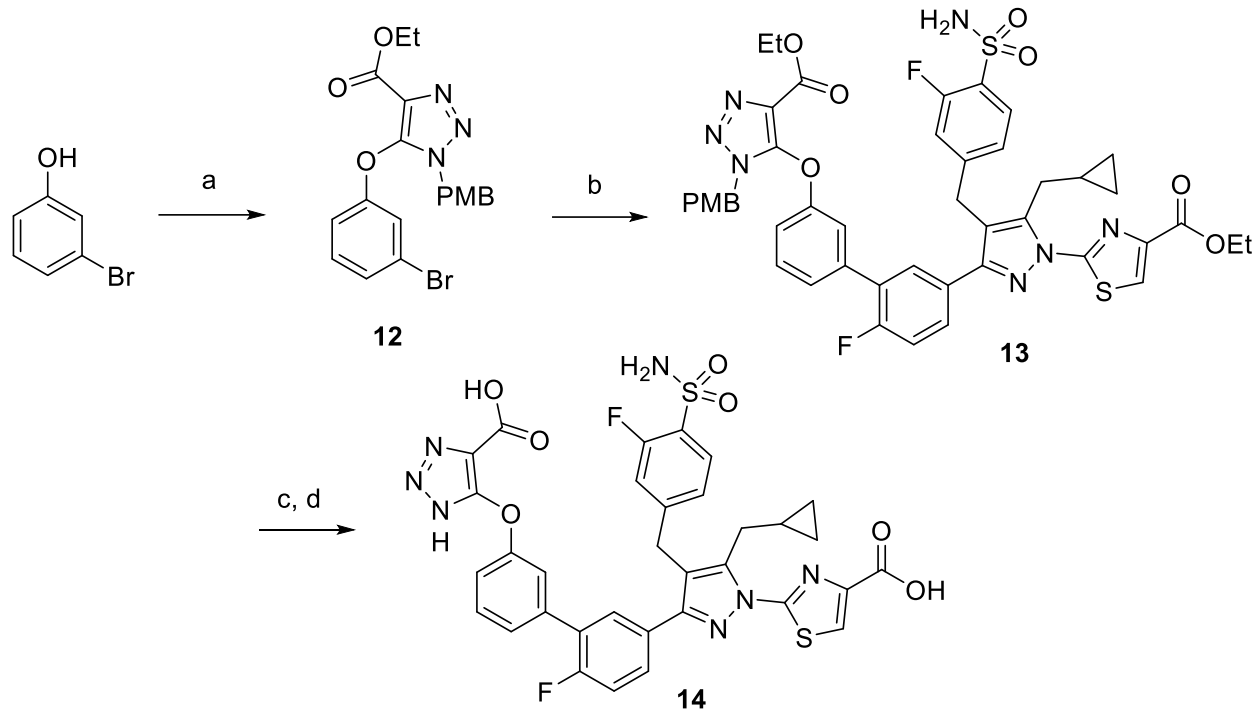

Step a: Preparation of ethyl 5-(3-bromophenoxy)-1-[(4-methoxyphenyl)methyl]triazole-4-carboxylate

Into a $200 \mathrm{~mL}$ round bottom flask was added ethyl 5-chloro-1-[(4-methoxyphenyl)methyl]triazole-4carboxylate (1.0 equiv, $1.0 \mathrm{~g}, 3.4 \mathrm{mmol}), m$-bromophenol $(1.0$ equiv, $590 \mathrm{mg}, 3.4 \mathrm{mmol})$, potassium carbonate $(3.0$ equiv, $1.4 \mathrm{~g}, 10 \mathrm{mmol})$ and DMF ( $11 \mathrm{~mL})$. The mixture was stirred at $130{ }^{\circ} \mathrm{C}$ for 2 hours. LCMS analysis indicated reaction was not completed. The mixture was stirred for additional 7 hours at $130^{\circ} \mathrm{C}$. The mixture was partitioned in a $1 \mathrm{~L}$ separatory funnel with $450 \mathrm{~mL}$ water and $150 \mathrm{~mL}$ of EtOAc. The aqueous layer was back extracted with EtOAc $(2 \times 150 \mathrm{~mL})$. The combined organic layers were concentrated and loaded directly on $20 \mathrm{~g}$ silica gel pre-cartridge. The mixture was purified by column chromatography through silica gel [ $80 \mathrm{~g}$ gold Teledyne silica gel cartridge] on a Teledyne ISCO Rf system, eluting with 100:0 to 30:70 hexanes:EtOAc as a gradient over 25 minutes, collecting all peaks. The desired product containing fractions were concentrated and dried under vacuum to afford a clear oil which crystallized slowly upon standing (1.4 g, 93\% yield).

Step b: Preparation of ethyl 2-[5-(cyclopropylmethyl)-3-[3-[3-[5-ethoxycarbonyl-3-[(4methoxyphenyl)methyl]triazol-4-yl]oxyphenyl]-4-fluoro-phenyl]-4-[(3-fluoro-4-sulfamoyl-phenyl)methyl]pyrazol-1yl]thiazole-4-carboxylate

Into a $20 \mathrm{~mL}$ reaction vial was added [5-[5-(cyclopropylmethyl)-1-(4-ethoxycarbonylthiazol-2-yl)-4-[(3fluoro-4-sulfamoyl-phenyl)methyl]pyrazol-3-yl]-2-fluoro-phenyl]boronic acid (1.0 equiv, $100 \mathrm{mg}, 0.2 \mathrm{mmol}$ ), $2 \mathrm{M}$ aqueous potassium phosphate solution $(3.0$ equiv, $0.25 \mathrm{~mL}, 0.50 \mathrm{mmol})$, [1,1'bis(diphenylphosphino)ferrocene]dichloropalladium(II) complex with dichloromethane $(0.05$ equiv, $7 \mathrm{mg}, 0.008$ $\mathrm{mmol}$ ), ethyl 5-(3-bromophenoxy)-1-[(4-methoxyphenyl)methyl]triazole-4-carboxylate (1.0 equiv, $72 \mathrm{mg}, 0.17$ $\mathrm{mmol}$ ) and 1,4-dioxane $(1.6 \mathrm{~mL})$. The mixture was purged with nitrogen for $10 \mathrm{~min}$, then heated at $130^{\circ} \mathrm{C}$ for $30 \mathrm{~min}$. The reaction mixture was loaded onto a $20 \mathrm{~g}$ silica gel pre-cartridge and dried under vacuum. The mixture was purified by column chromatography through silica gel [24g gold Teledyne silica gel cartridge] on a Teledyne ISCO Rf system, eluting with 95:5 to 0:100 hexanes:EtOAc as a gradient over 20 minutes, collecting all peaks. The desired 
product containing fractions were concentrated and dried under vacuum to afford a clear oil which crystallized slowly upon standing (91 mg, 60\% yield).

Step $\mathbf{c}$ and d: Preparation of 2-[3-[3-[3-[(5-carboxy-1H-triazol-4-yl)oxy]phenyl]-4-fluoro-phenyl]-5(cyclopropylmethyl)-4-[(3-fluoro-4-sulfamoyl-phenyl)methyl]pyrazol-1-yl]thiazole-4-carboxylic acid

Into a $10 \mathrm{~mL}$ reaction vial was added ethyl 2-[5-(cyclopropylmethyl)-3-[3-[3-[5-ethoxycarbonyl-3-[(4methoxyphenyl)methyl]triazol-4-yl]oxyphenyl]-4-fluoro-phenyl]-4-[(3-fluoro-4-sulfamoyl-phenyl)methyl]pyrazol-1yl]thiazole-4-carboxylate (1.0 equiv, $91 \mathrm{mg}, 0.10 \mathrm{mmol}), \mathrm{CH}_{2} \mathrm{Cl}_{2}(0.15 \mathrm{~mL}$ ) and triethylsilane (3.1 equiv, $0.050 \mathrm{~mL}$, $0.31 \mathrm{mmol}$ ). The mixture was stirred for $2 \mathrm{~min}$ at $23^{\circ} \mathrm{C}$. Trifluoroacetic acid ( 53 equiv, $0.60 \mathrm{~mL}, 5.3 \mathrm{mmol}$ ) was added dropwise. The reaction was heated at $50^{\circ} \mathrm{C}$ and monitored by LCMS. After stirring at $50^{\circ} \mathrm{C}$ for 4 hours, LCMS analysis indicated completion of reaction. The mixture was concentrated and injected directly onto a preparative HPLC column (ACCQPrep HP125 UV). Purification by a reverse phase preparative HPLC column chromatography (C18 column dimensions: $20 \mathrm{~mm} \times 150 \mathrm{~mm}, 5 \mu \mathrm{m}$ ), eluting with $90: 10$ to 0:100 water:MeCN $+0.1 \%$ formic acid as a gradient over 35 minutes, collecting all peaks. The desired product containing fractions were concentrated and lyophilized overnight to yield the di-ester product as a white powder ( $47 \mathrm{mg}, 59 \%$ yield).

The di-ester product was treated with $1 \mathrm{M}$ aqueous $\mathrm{LiOH} / \mathrm{THF} / \mathrm{MeOH}(\mathrm{v} / \mathrm{v} / \mathrm{v}, 1 / 1 / 1,0.6 \mathrm{~mL})$ and stirred at $23^{\circ} \mathrm{C}$ for 18 hours. LCMS analysis indicated completion of hydrolysis. The reaction was quenched with concentrated formic acid until the $\mathrm{pH}$ was $\sim 2$. The mixture was concentrated and injected directly onto a preparative HPLC column (ACCQPrep HP125 UV). Purification by a reverse phase preparative HPLC column chromatography (C18 column dimensions: $20 \mathrm{~mm} \times 150 \mathrm{~mm}, 5 \mu \mathrm{m}$ ), eluting with 90:10 to 0:100 water:MeCN $+0.1 \%$ formic acid as a gradient over 25 minutes, collecting all peaks. The desired product containing fractions were concentrated and lyophilized overnight to yield the title product as a white powder (15 mg, $15 \%$ yield). ${ }^{1} \mathrm{H} \mathrm{NMR}\left(400 \mathrm{MHz}, \mathrm{CD}_{3} \mathrm{OD}\right) \delta 8.18(\mathrm{~s}, 1 \mathrm{H})$, $7.73(\mathrm{t}, J=7.7 \mathrm{~Hz}, 1 \mathrm{H}), 7.64-7.57(\mathrm{~m}, 2 \mathrm{H}), 7.43(\mathrm{t}, J=8.0 \mathrm{~Hz}, 1 \mathrm{H}), 7.27-7.02(\mathrm{~m}, 6 \mathrm{H}), 4.19(\mathrm{~s}, 2 \mathrm{H}), 3.26(\mathrm{~d}, J=6.8$ $\mathrm{Hz}, 3 \mathrm{H}), 1.18-1.07(\mathrm{~m}, 1 \mathrm{H}), 0.42-0.34(\mathrm{~m}, 2 \mathrm{H}), 0.26-0.21(\mathrm{~m}, 2 \mathrm{H})$. LC-MS (ESI) $\mathrm{m} / \mathrm{z} 734(\mathrm{M}+\mathrm{H})^{+} ;\left[(\mathrm{M}+\mathrm{H})^{+}\right.$calculated for $\left.\mathrm{C}_{33} \mathrm{H}_{25} \mathrm{~F}_{2} \mathrm{~N}_{7} \mathrm{O}_{7} \mathrm{~S}_{2}, 733.72\right]$.

Preparation of 2-(3-(4'-((5-carboxy-1H-1,2,3-triazol-4-yl)oxy)-6-fluoro-[1,1'-biphenyl]-3-yl)-5-(cyclopropylmethyl)4-(3-fluoro-4-sulfamoylbenzyl)-1H-pyrazol-1-yl)thiazole-4-carboxylic acid (Compound 15)

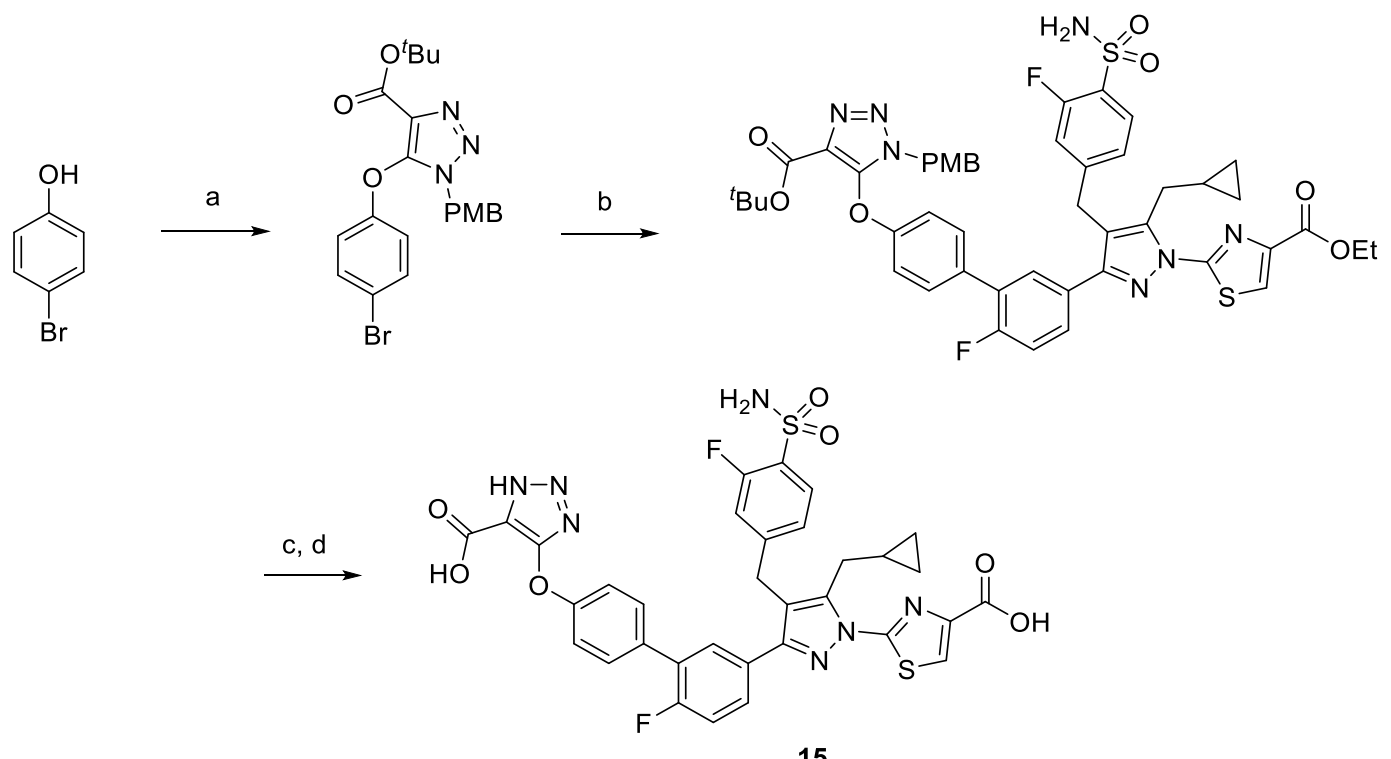


Compound 15 was prepared in the same manner as described in above synthesis of Compound 14, starting from para-bromophenol. ${ }^{1} \mathrm{H}$ NMR $\left(400 \mathrm{MHz}, d_{6}\right.$-DMSO) $\delta 13.19(\mathrm{br} \mathrm{s}, 1 \mathrm{H}), 8.31(\mathrm{~s}, 1 \mathrm{H}), 7.68(\mathrm{t}, J=7.9 \mathrm{~Hz}, 1 \mathrm{H}), 7.62$ $(\mathrm{d}, J=2.6 \mathrm{~Hz}, 1 \mathrm{H}), 7.59(\mathrm{br} \mathrm{s}, 3 \mathrm{H}), 7.46-7.40(\mathrm{~m}, 1 \mathrm{H}), 7.41-7.32(\mathrm{~m}, 2 \mathrm{H}), 7.22-7.12(\mathrm{~m}, 3 \mathrm{H}), 7.08(\mathrm{~d}, J=8.1 \mathrm{~Hz}$, $1 \mathrm{H}), 4.19(\mathrm{~s}, 2 \mathrm{H}), 3.18(\mathrm{~d}, J=6.9 \mathrm{~Hz}, 2 \mathrm{H}), 1.22-1.11(\mathrm{~m}, 1 \mathrm{H}), 0.38-0.32(\mathrm{~m}, 2 \mathrm{H}), 0.27-0.19(\mathrm{~m}, 2 \mathrm{H})$. LC-MS (ESI) $\mathrm{m} / \mathrm{z} 734(\mathrm{M}+\mathrm{H})^{+} ;\left[(\mathrm{M}+\mathrm{H})^{+}\right.$calculated for $\left.\mathrm{C}_{33} \mathrm{H}_{25} \mathrm{~F}_{2} \mathrm{~N}_{7} \mathrm{O}_{7} \mathrm{~S}_{2}, 733.72\right]$.

Preparation of 2-(3-(4'-((5-carboxy-1H-1,2,3-triazol-4-yl)thio)-6-fluoro-[1,1'-biphenyl]-3-yl)-5(cyclopropylmethyl)-4-(3-fluoro-4-sulfamoylbenzyl)-1H-pyrazol-1-yl)thiazole-4-carboxylic acid (Compound 16)

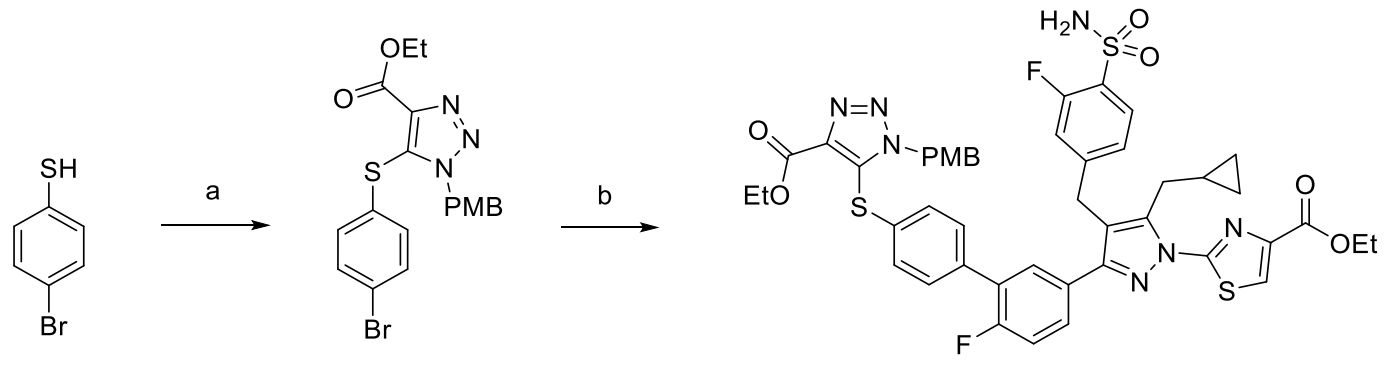<smiles>NS(=O)(=O)c1ccc(Cc2c(-c3ccc(F)c(-c4ccc(Sc5nn[nH]c5C(=O)O)cc4)n3)nn(-c3nc(C(=O)O)cs3)c2CC2CC2)cc1F</smiles>

Compound 16 was prepared in the same manner as described in above synthesis of Compound 14, starting from para-bromothiophenol. ${ }^{1} \mathrm{H}$ NMR $\left(400 \mathrm{MHz}, d_{6}\right.$-DMSO) $\delta 8.31(\mathrm{~s}, 1 \mathrm{H}), 7.67(\mathrm{t}, J=8.0 \mathrm{~Hz}, 2 \mathrm{H}), 7.65-7.59(\mathrm{~m}, 3 \mathrm{H})$, $7.55-7.47(\mathrm{~m}, 2 \mathrm{H}), 7.46-7.35(\mathrm{~m}, 3 \mathrm{H}), 7.18(\mathrm{~d}, J=11.2 \mathrm{~Hz}, 1 \mathrm{H}), 7.07(\mathrm{~d}, J=8.2 \mathrm{~Hz}, 1 \mathrm{H}), 4.19(\mathrm{~s}, 2 \mathrm{H}), 3.18(\mathrm{~d}, J=6.9$ $\mathrm{Hz}, 2 \mathrm{H}), 1.21-1.09(\mathrm{~m}, 1 \mathrm{H}), 0.38-0.31(\mathrm{~m}, 2 \mathrm{H}), 0.26-0.20(\mathrm{~m}, 2 \mathrm{H})$. LC-MS (ESI) $\mathrm{m} / \mathrm{z} 749(\mathrm{M}+\mathrm{H})^{+} ;\left[(\mathrm{M}+\mathrm{H})^{+}\right.$calculated for $\left.\mathrm{C}_{33} \mathrm{H}_{25} \mathrm{~F}_{2} \mathrm{~N}_{7} \mathrm{O}_{6} \mathrm{~S}_{3}, 749.78\right]$.

Preparation of 2-(3-(4'-(5-carboxy-1H-1,2,3-triazol-4-yl)-6-fluoro-[1,1'-biphenyl]-3-yl)-5-(cyclopropylmethyl)-4-(3fluoro-4-sulfamoylbenzyl)-1H-pyrazol-1-yl)thiazole-4-carboxylic acid (Compound 17) 

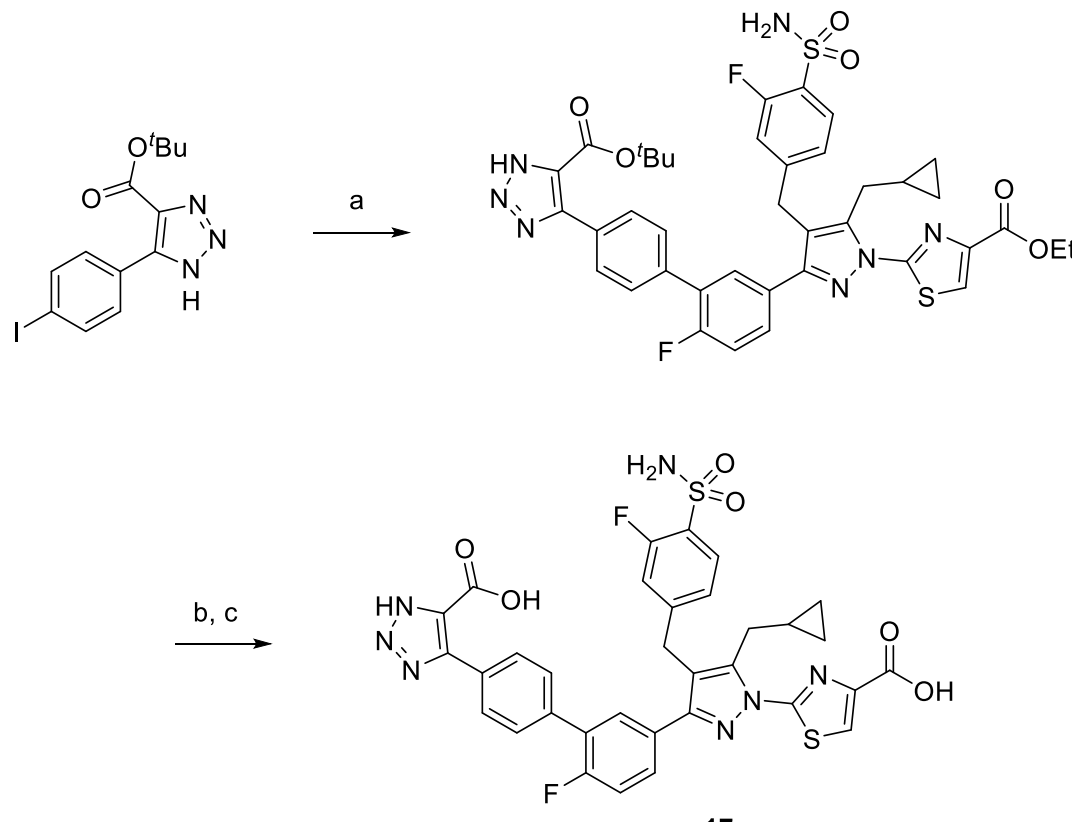

17

Step a: Preparation of ethyl 2-(3-(4'-(5-(tert-butoxycarbonyl)-1H-1,2,3-triazol-4-yl)-6-fluoro-[1,1'-biphenyl]3-yl)-5-(cyclopropylmethyl)-4-(3-fluoro-4-sulfamoylbenzyl)-1H-pyrazol-1-yl)thiazole-4-carboxylate

Into a $20 \mathrm{~mL}$ reaction vial was added ethyl 2-[5-(cyclopropylmethyl)-4-[(3-fluoro-4-sulfamoylphenyl)methyl]-3-[4-fluoro-3-(4,4,5,5-tetramethyl-1,3,2-dioxaborolan-2-yl)phenyl]pyrazol-1-yl]thiazole-4-

carboxylate (1.0 equiv, $200 \mathrm{mg}, 0.3 \mathrm{mmol}$ ), $2 \mathrm{M}$ aqueous potassium phosphate solution (3.0 equiv, $0.44 \mathrm{~mL}, 0.88$ $\mathrm{mmol}$ ), [1,1'-bis(diphenylphosphino)ferrocene]dichloropalladium(II), complex with dichloromethane (0.1 equiv, 24 $\mathrm{mg}, 0.03 \mathrm{mmol}$ ), tert-butyl 4-(4-iodophenyl)- $1 \mathrm{H}$-triazole-5-carboxylate (1.0 equiv, $110 \mathrm{mg}, 0.29 \mathrm{mmol}$ ) and 1,4dioxane $(1.7 \mathrm{~mL})$. The mixture was purged with nitrogen for $10 \mathrm{~min}$, then heated at $100^{\circ} \mathrm{C}$ for $30 \mathrm{~min}$. LCMS analysis indicated completion of reaction. The mixture was concentrated under reduced pressure, loaded onto a $20 \mathrm{~g}$ silica gel pre-cartridge and dried under vacuum. The mixture was purified by column chromatography through silica gel [40 g gold Teledyne silica gel cartridge] on a Teledyne ISCO Rf system, eluting with 95:5 to 0:100 hexanes:EtOAc as a gradient over 25 minutes, collecting all peaks. The desired product containing fractions were concentrated and dried under vacuum to afford a clear oil which crystallized slowly upon standing (104 mg, 44\% yield).

Step b and c: Preparation of 2-(3-(4'-(5-carboxy-1H-1,2,3-triazol-4-yl)-6-fluoro-[1,1'-biphenyl]-3-yl)-5(cyclopropylmethyl)-4-(3-fluoro-4-sulfamoylbenzyl)-1H-pyrazol-1-yl)thiazole-4-carboxylic acid

Into a reaction vial was added ethyl 2-[3-[3-[4-(5-tert-butoxycarbonyl-1H-triazol-4-yl)phenyl]-4-fluorophenyl]-5-(cyclopropylmethyl)-4-[(3-fluoro-4-sulfamoyl-phenyl)methyl]pyrazol-1-yl]thiazole-4-carboxylate equiv, $104 \mathrm{mg}, 0.13 \mathrm{mmol})$, dichloromethane $(0.4 \mathrm{~mL}$ ) and triethylsilane (9.6 equiv, $0.20 \mathrm{~mL}, 1.3 \mathrm{mmol})$. The mixture was stirred for $2 \mathrm{~min}$ at $23^{\circ} \mathrm{C}$. Trifluoroacetic acid (41 equiv, $0.60 \mathrm{~mL}, 5.3 \mathrm{mmol}$ ) was added dropwise. The reaction was heated at $50{ }^{\circ} \mathrm{C}$ and monitored by LCMS. After stirring at $50{ }^{\circ} \mathrm{C}$ for 4 hours, LCMS analysis indicated completion of reaction. The mixture was concentrated and injected directly onto a preparative HPLC column (ACCQPrep HP125 UV). Purification by reverse phase preparative HPLC column chromatography (C18 column dimensions: $20 \mathrm{~mm} \times 150$ $\mathrm{mm}, 5 \mu \mathrm{m})$, eluting with 90:10 to 0:100 water:MeCN $+0.1 \%$ formic acid as a gradient over 35 minutes, collecting all peaks. The desired product containing fractions were concentrated and lyophilized overnight to yield 4-(5'-(5(cyclopropylmethyl)-1-(4-(ethoxycarbonyl)thiazol-2-yl)-4-(3-fluoro-4-sulfamoylbenzyl)-1H-pyrazol-3-yl)-2'-fluoro[1,1'-biphenyl]-4-yl)-1H-1,2,3-triazole-5-carboxylic acid as a white powder (54 mg, 55\% yield). 
The ester product was treated with $1 \mathrm{M}$ aqueous $\mathrm{LiOH} / \mathrm{THF} / \mathrm{MeOH}(1.5 \mathrm{~mL}, \mathrm{v} / \mathrm{v} / \mathrm{v}, 1 / 1 / 1)$ and stirred at $23^{\circ} \mathrm{C}$ for 18 hours. LCMS analysis indicated completion of hydrolysis. The reaction was quenched with concentration formic acid until the $\mathrm{pH}$ was acidic. The mixture was concentrated and injected directly onto a preparative HPLC column (ACCQPrep HP125). Purificaiton by reverse phase preparative HPLC column chromatography (C18 column dimensions: $20 \mathrm{~mm} \times 150 \mathrm{~mm}, 5 \mu \mathrm{m}$ ), eluting with 90:10 to 0:100 water:MeCN $+0.1 \%$ formic acid as a gradient over 25 minutes, collecting all peaks. The desired product containing fractions were concentrated and lyophilized overnight to yield the title product as a white powder ( $35 \mathrm{mg}, 37 \%$ yield). ${ }^{1} \mathrm{H}$ NMR (400 MHz, $d_{6}$-DMSO) $\delta 13.30-$ $13.00(\mathrm{~m}, 1 \mathrm{H}), 8.29(\mathrm{~s}, 1 \mathrm{H}), 8.05-7.80(\mathrm{~m}, 2 \mathrm{H}), 7.68-7.55(\mathrm{~m}, 4 \mathrm{H}), 7.55-7.45(\mathrm{~m}, 2 \mathrm{H}), 7.39(\mathrm{t}, J=9.6 \mathrm{~Hz}, 1 \mathrm{H}), 7.17$ $(\mathrm{d}, J=11.1 \mathrm{~Hz}, 1 \mathrm{H}), 7.07(\mathrm{~d}, J=8.1 \mathrm{~Hz}, 1 \mathrm{H}), 4.18(\mathrm{~s}, 2 \mathrm{H}), 3.16(\mathrm{~d}, J=7.0 \mathrm{~Hz}, 2 \mathrm{H}), 1.20-1.05(\mathrm{~m}, 1 \mathrm{H}), 0.37-0.29(\mathrm{~m}$, $2 \mathrm{H}), 0.24-0.17(\mathrm{~m}, 2 \mathrm{H})$. LC-MS (ESI) $\mathrm{m} / 2718(\mathrm{M}+\mathrm{H})^{+}$; [(M+H) calculated for $\left.\mathrm{C}_{33} \mathrm{H}_{25} \mathrm{~F}_{2} \mathrm{~N}_{7} \mathrm{O}_{6} \mathrm{~S}_{2}, 717.72\right]$.

\section{Human GO Production and Purification:}

The method was previously described by Murray et al $1^{1}$. Briefly, C41(DE3) Escherichia coli cells containing pET28a-HAOX1 plasmid were grown in LB Miller $+50 \mathrm{ug} / \mathrm{ml}$ kanamycin at $37^{\circ} \mathrm{C}$ to an $\mathrm{OD}_{600}$ of 0.8 . The culture temperature was decreased to $16^{\circ} \mathrm{C}$, and protein expression was induced overnight by adding $0.5 \mathrm{mM}$ IPTG. Cells were harvested by centrifugation and stored at $-80^{\circ} \mathrm{C}$ until further use. Cells were lysed in the presence of 0.05 $\mathrm{mg} / \mathrm{ml} \mathrm{FMN} \mathrm{in} \mathrm{buffer} \mathrm{A} \mathrm{[20} \mathrm{mM} \mathrm{HEPES} \mathrm{pH} \mathrm{7.9,} 500 \mathrm{mM} \mathrm{KCl,} 5 \mathrm{mM}$ imidazole, 10\% glycerol, $0.1 \%$ Triton X-100, 0.1 $\mu \mathrm{g} / \mathrm{ml}$ benzamidine, $0.1 \mu \mathrm{g} / \mathrm{ml} \mathrm{PMSF}, 1 \mathrm{mM} \mathrm{MgCl}$, and $0.005 \%$ DNAse I], using an Avestin Emulsiflex C3 homogenizer at 15,000-20,000 psi (3 passes). The lysate was cleared by centrifugation at 39,000 x g for $45 \mathrm{~min}$. The His-tagged protein was isolated from a cobalt NTA column (HisPur Cobalt Superflow Agarose; Thermo 25229), using a 5-250 $\mathrm{mM}$ imidazole gradient in buffer A without Triton X-100 and glycerol. The pooled fractions were dialyzed overnight against $20 \mathrm{mM}$ HEPES pH 7.5, $100 \mathrm{mM} \mathrm{NaCl}, 10 \%$ glycerol and $0.1 \mathrm{mM}$ EDTA. Biotinylated thrombin $(0.1 \mathrm{U} / \mathrm{mg})$ was added to the dialysis bag to cleave the His-tag. Cleavage was confirmed via mass spectrometry. The salt content of the buffer was increased to $500 \mathrm{mM} \mathrm{NaCl}$ to facilitate protein concentration. Excess $\mathrm{FMN}$ was added to the protein for $1 \mathrm{~h}$ prior to concentration and separation over a Superdex 200 column with $20 \mathrm{mM} \mathrm{HEPES} \mathrm{pH7.5,500} \mathrm{mM} \mathrm{NaCl,}$ $10 \%$ glycerol. Pooled fractions were concentrated with 10,000 MWCO centrifugal concentrator (Sartorius Vivaspin 20, CS2002). Aliquots of protein were flash frozen with liquid nitrogen and stored at $-80^{\circ} \mathrm{C}$.

\section{Human LDHA Production and Purification:}

BL21 gold (DE3) E. coli cells containing the LDHA-pET28b plasmid were grown at $37^{\circ} \mathrm{C}$ to an $\mathrm{OD}_{600}$ of 0.8 . The expression protocol, buffers used, lysis and affinity column conditions were the same as for GO above. LDHA containing fractions were pooled and dialyzed into $20 \mathrm{mM} \mathrm{HEPES} \mathrm{pH} \mathrm{7.5,100} \mathrm{mM} \mathrm{NaCl}$, and $0.2 \mathrm{mM}$ EDTA. For this protein the His-tag was not removed. The dialyzed protein was filtered $(0.2 \mu \mathrm{m})$, concentrated, and passed over a Superdex 200 size exclusion column and stored as indicated above.

\section{Crystallization and Structure Determination:}

Briefly, crystals of GO and LDHA were obtained by co-crystallization with compound $\mathbf{1 5}$ (5-fold molar excess). Crystals were cryo protected and flash frozen directly in the $100 \mathrm{~K}$ nitrogen cryo stream. Data were collected on a rotating anode home X-ray diffractometer (Rigaku Micromax 007 X-ray source with VariMax-HF Confocal Optic System coupled to Pilatus $3 \mathrm{M}$ detector) operated at $40 \mathrm{kV}$ and $20 \mathrm{~mA}$. The data were integrated and scaled with HKL-3000. Both the structures were solved by molecular replacement using GO (PDB code 2RDT) and LDHA (PDB code $5 \mathrm{~W} 8 \mathrm{I}$ ) as search models. ${ }^{1,2}$ Models were prepared by trimming off all the non-protein molecules and active site residues. Models were manually rebuilt in COOT and refined with REFMAC. ${ }^{3,4}$ Model validation was performed with PROCHECK and MOLPROBITY. ${ }^{5,6}$ Details of crystallization conditions, structure solution and refinement statistics are summarized in Table S1. Figures were prepared with PyMOL (Shrödinger). 
Table S1. Data Collection and Refinement Statistics

\begin{tabular}{|c|c|c|}
\hline Dataset & GO-compound 15 & LDHA-compound 15 \\
\hline \multicolumn{3}{|l|}{ Data Collection } \\
\hline X-ray source & MicroMax-007 & MicroMax-007 \\
\hline Wavelength $(\AA)$ & 1.5418 & 1.5418 \\
\hline Resolution range $(\AA)$ & $\begin{array}{l}50.00-2.07 \\
(2.11-2.07)\end{array}$ & $\begin{array}{l}50.00-2.50 \\
(2.54-2.50)\end{array}$ \\
\hline Space group & 14 & 1121 \\
\hline Unit cell $\left(\AA{ }^{\circ}{ }^{\circ}\right)$ & $\begin{array}{l}96.996 .979 .5 \\
909090\end{array}$ & $\begin{array}{l}83.9131 .0215 .5 \\
9099.390\end{array}$ \\
\hline Total reflections & 134115 & 364240 \\
\hline Unique reflections & $22486(1133)$ & 78979 (3992) \\
\hline Multiplicity & $6.0(2.0)$ & $4.6(2.9)$ \\
\hline Completeness (\%) & $99.9(99.4)$ & $100(99.9)$ \\
\hline 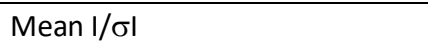 & $14.6(3.2)$ & $13.5(3.0)$ \\
\hline Wilson B-factor $\left(\AA^{2}\right)$ & 17.9 & 31.9 \\
\hline R-merge & $0.095(0.273)$ & $0.104(0.407)$ \\
\hline R-meas & $0.103(0.364)$ & $0.117(0.497)$ \\
\hline R-pim & $0.040(0.239)$ & $0.053(0.280)$ \\
\hline $\mathrm{CC}^{1 / 2}$ (highest resolution shell) & 0.797 & 0.870 \\
\hline CC* (highest resolution shell) & 0.942 & 0.965 \\
\hline \multicolumn{3}{|l|}{ Refinement } \\
\hline Reflections used in refinement & $21419(1534)$ & 74825 (4086) \\
\hline Reflections used for R-free & $1065(85)$ & $3910(213)$ \\
\hline R-work & 0.1259 & 0.2093 \\
\hline R-free & 0.1660 & 0.2576 \\
\hline Number of non-hydrogen atoms & 2972 & 11585 \\
\hline macromolecules & 2651 & 10187 \\
\hline solvent & 202 & 539 \\
\hline ligands & 119 & 859 \\
\hline RMS(bonds) & 0.011 & 0.008 \\
\hline RMS(angles) & 1.754 & 1.461 \\
\hline Ramachandran favored (\%) & 93.2 & 92.5 \\
\hline Ramachandran allowed (\%) & 5.4 & 7.4 \\
\hline Generously allowed (\%) & 1.4 & \\
\hline Clashscore & 4.5 & 2.79 \\
\hline \multicolumn{3}{|l|}{ Average B-factor $\left(\AA^{2}\right)$} \\
\hline macromolecules & 21.4 & 39.47 \\
\hline solvent & 29.3 & 40.24 \\
\hline Cryo & $\begin{array}{l}20 \% \text { Ethylene } \\
\text { Glycol in mother liquor }\end{array}$ & $\begin{array}{l}\text { 20\% Ethylene } \\
\text { Glycol in mother liquor }\end{array}$ \\
\hline Crystallization conditions & $\begin{array}{l}0.1 \text { M Tris- } \mathrm{HCl} \text { pH } 8.5 \\
25 \%(w / v) \text { PEG } 1000\end{array}$ & $\begin{array}{l}0.2 \text { M Lithium Sulfate } \\
0.1 \text { M Sodium Cacodylate: } \mathrm{HCl} \mathrm{pH} 6.5 \\
30 \% \text { (v/v) PEG } 400\end{array}$ \\
\hline PDB code & $7 \mathrm{M} 2 \mathrm{O}$ & $7 \mathrm{M} 2 \mathrm{~N}$ \\
\hline
\end{tabular}




\section{LDHA Biochemical Assay:}

Briefly, compounds were serially diluted (3-fold in 100\% DMSO) for a 10-concentration dose response. A solution of $50 \mu \mathrm{L}$ of diluted recombinant human LDHA (WFSM - Lowther Lab) or mouse LDHA (Creative Biomart) in assay buffer (50 mM Tris pH 7.5 and $100 \mathrm{mM} \mathrm{NaCl}$ ) was preincubated with $1 \mu \mathrm{L}$ compound in black, clear bottom plates (Greiner Bio-One) at room temperature for $10 \mathrm{~min}$. The reaction was initiated with the addition of $50 \mu \mathrm{L}$ of diluted sodium pyruvate (Sigma Aldrich) and NADH (Sigma Aldrich). The plate was shaken briefly and immediately transferred to an absorbance plate reader. The oxidation of NADH was tracked at $340 \mathrm{~nm}$ for $15 \mathrm{~min}$. The final assay conditions had $0.035 \mu \mathrm{g} / \mathrm{mL}$ hLDHA or $0.012 \mu \mathrm{L} / \mathrm{mL} \mathrm{mLDHA}, 50 \mu \mathrm{M}$ sodium pyruvate, $50 \mu \mathrm{M}$ NADH, and $1 \%$ DMSO.

\section{GO Biochemical Assay:}

Briefly, compounds were serially diluted (3-fold in 100\% DMSO) for a 10-concentration dose response. A solution of $50 \mu \mathrm{L}$ of diluted recombinant human GO (WFSM - Lowther Lab) or mouse GO (Creative Biomart) in assay buffer ( $25 \mathrm{mM}$ HEPES pH 8.0) was preincubated with $1 \mu \mathrm{L}$ compound in black, opaque plates (Greiner Bio-One) at room temperature for $10 \mathrm{~min}$. The reaction was initiated with the addition of $50 \mu \mathrm{L}$ of a diluted substrate mixture of glycolate (Sigma Aldrich), horseradish peroxidase (Sigma Aldrich), and Amplex Red (Invitrogen). The plate was shaken briefly and immediately transferred to a fluorescent plate reader. Fluorescence was obtained from the reaction of $\mathrm{H}_{2} \mathrm{O}_{2}$ and Amplex Red and tracked for $10 \mathrm{~min}$ (Ex: $544 \mathrm{~nm}$, Em: $590 \mathrm{~nm}$ ). The final assay conditions had $0.04 \mu \mathrm{g} / \mathrm{mL}$ hGO or $0.4 \mu \mathrm{g} / \mathrm{mL} \mathrm{mGO}, 60 \mu \mathrm{M}$ glycolate, $0.01 \mathrm{U} / \mathrm{mL} \mathrm{HRP}, 50 \mu \mathrm{M}$ Amplex Red, and 1\% DMSO.

\section{Mouse Primary Hepatocyte Assay}

A mouse model with hepatic knockdown of the Agxt gene was developed. The model was generated through systemic administration of $0.4 \mathrm{mg} / \mathrm{kg}$ siRNA to CD1 male mice (8-12 weeks of age, Charles River Labs). The Agxt siRNA was encapsulated in a lipid nanoparticle (XL-10 (KL-52) LNP as described in WO2016/205410) and its sequence was: 5'-AcAAcuGGAGGGAcAucGudTsdT-3' (modified sense strand sequence, N: RNA residues; dN: DNA residues; n: 2'-O-methyl residues; s: phosphorothioate residues) and 5'-ACGAUGUCCCUCCAGUUGUdTsdT-3' (modified antisense strand sequence, see annotation above for residue modifications). Administration of the Agxt siRNA was done intravenously on day 0 and day 7 to maintain $>90 \%$ knockdown of hepatic Agxt expression throughout the experimental study. The Agxt-KD model presented robust elevation of the urinary oxalate excretion within 7 days post-administration to a similar extent as Agxt-null mice. ${ }^{7}$

Hepatocytes from naïve CD1 or Agxt knockdown mice were freshly isolated on the day of the assay. In brief, mouse portal vein was cannulated and perfused at a flow of $2 \mathrm{~mL} / \mathrm{min}$ and the inferior vena cava was cut for drainage. The liver was perfused in HBSS containing $10 \mathrm{mM} \mathrm{HEPES}$ at $\mathrm{pH} 7.4$ for $4 \mathrm{~min}$ at $10 \mathrm{~mL} / \mathrm{min}$ followed by perfusion in the digestion media (HBSS, $10 \mathrm{mM}$ HEPES, $\mathrm{pH}$ 7.4, $1 \mathrm{mM} \mathrm{CaCl} 2$ and $50 \mathrm{U} / \mathrm{mL}$ collagenase (Fisher \#NC9919937)) for $10 \mathrm{~min}$ at $10 \mathrm{~mL} / \mathrm{min}$. The liver membrane was then disrupted in the hepatocyte wash media (Fisher \#17704024) on ice, and the dissociated hepatocytes were washed twice in the hepatocyte wash media. Cells were then resuspended in $30 \mathrm{~mL}$ hepatocyte wash media and $20 \mathrm{~mL}$ of Percoll solution was added followed by centrifugation at $120 \mathrm{xg}$ for $4 \mathrm{~min}$. Mouse hepatocytes were resuspended in suspension media (Krebs-Henseleit Buffer, $5 \mathrm{mM}$ HEPES, pH 7.4) and incubated at $37{ }^{\circ} \mathrm{C}$ for up to $2 \mathrm{~h}$ with shaking at $900 \mathrm{rpm}$ in $5 \% \mathrm{CO}_{2}$ before use. To assess the potency of compounds in blocking the conversion of pyruvate to lactate in naïve mouse hepatocytes or the conversion of glycolate to oxalate in Agxt knockdown mouse primary hepatocytes, compounds were serially diluted in assay buffer (Krebs-Heinseleit Buffer, $1 \mathrm{M} \mathrm{HEPES,} \mathrm{pH} \mathrm{7.4,} \mathrm{0.2 \%} \mathrm{DMSO)} \mathrm{containing} \mathrm{either} 2 \mathrm{mM}$ pyruvate or $10 \mathrm{mM}$ glycolate. Equal volumes of diluted compounds were incubated with naïve mouse hepatocytes (50 $\mu \mathrm{L}$, 100,000 cells/well) or Agxt knockdown hepatocytes (100 $\mu \mathrm{L}, 200,000$ cells/well) in Krebs-Heinseleit Buffer, $1 \mathrm{M}$ HEPES, pH 7.4 at $37^{\circ} \mathrm{C}$ in $5 \% \mathrm{CO}_{2}$ with shaking at $900 \mathrm{rpm}$. To measure the levels of pyruvate to lactate conversion 
in naïve mouse hepatocytes, after 30 min compound incubation the cells were quenched with $100 \mu \mathrm{M}{ }^{13} \mathrm{C}$-lactate in acetonitrile. The cells were then centrifuged for $10 \mathrm{~min}$ at $3700 \mathrm{rpm}$ and $100 \mu \mathrm{L}$ of supernatant was transferred to a new plate and mixed with $100 \mu \mathrm{L} \mathrm{H}_{2} \mathrm{O}$ before being injected into LC-MS for pyruvate and lactate quantification. Chromatographic separation was performed using an Agilent Zorbax XDB-18 $4.6 \times 50$ mm column, with $0.1 \%$ acetic acid in water (mobile phase $A$ ) and acetonitrile (mobile phase $B$ ) run at $1 \mathrm{~mL} / \mathrm{min}$ as per the following gradient: $5 \%$ B for $1 \mathrm{~min}, 5-95 \%$ B over $0.5 \mathrm{~min}, 95 \%$ B for $1 \mathrm{~min}, 95-5 \%$ B over $0.1 \mathrm{~min}$, and $5 \%$ B for $1.50 \mathrm{~min}$. The samples were analyzed using Sciex 4000 mass spectrometer operated in multiple reaction monitoring (MRM) mode under negative ionization. The MRM transitions were $\mathrm{m} / \mathrm{z} 89$ to $\mathrm{m} / \mathrm{z} 43$ for lactate and $\mathrm{m} / \mathrm{z} 90$ to $\mathrm{m} / \mathrm{z} 44$ for ${ }^{13} \mathrm{C}$-lacate. To measure the conversion of glycolate to oxalate in Agxt knockdown mouse hepatocytes, after $2 \mathrm{~h}$ compound incubation the cells were centrifuged at $2 \mathrm{~min}$ at $3200 \times \mathrm{g}$, and $100 \mu \mathrm{L}$ of supernatant was transferred to a new plate and mixed with $10 \mu \mathrm{L}$ of $1 \mathrm{~N}$ aqueous $\mathrm{HCl}$ solution to bring the $\mathrm{pH}<2.0$. Acidification both limits potential non-enzymatic breakdown of ascorbic acid to oxalate and loss of oxalate through crystallization of calcium oxalate. The amount of oxalate in each sample was then quantified by ion chromatography coupled with negative electrospray mass spectrometry at $U A B$, as previously described. ${ }^{8}$

\section{Mouse PK/PD experiment of Compound 7 and 14:}

Male C57BL/6 mice were purchased from Charles River Laboratories. The animals were 8 weeks old with body weights $20-23 \mathrm{~g}$ on the dosing date. The animals were housed in a 12-h light/12-h dark cycle environment, having access to standard rodent chow and water ad libitum. Compound $\mathbf{7}$ and $\mathbf{1 4}$ were formulated as a solution at a dose volume of $10 \mathrm{mg} / \mathrm{mL}$ in $0.5 \%$ methylcellulose containing 2 equivalents of sodium hydroxide. Both compounds were orally administered to three mice per group at a dose of $100 \mathrm{mg} / \mathrm{kg}$. At $6 \mathrm{~h}$, animals were anesthetized using isoflurane, blood samples were collected into pre-cooled tubes containing $K_{3}$-EDTA from each animal via cardiac puncture. These blood samples were maintained on ice and centrifuged within an hour at $6000 \mathrm{xg}$ for $10 \mathrm{~min}$ at 4 ${ }^{\circ} \mathrm{C}$ to obtain plasma. The plasma samples were collected into polypropylene tubes, quickly frozen on dry ice and stored at $-80{ }^{\circ} \mathrm{C}$ until analysis. Following blood collection, animals were euthanized by cervical dislocation under deep isoflurane anesthesia, and a piece of liver ( $100-200 \mathrm{mg})$ was collected, snap frozen in liquid nitrogen, and then stored at $-80^{\circ} \mathrm{C}$ until analysis.

\section{PK Analysis}

To quantify Compound $\mathbf{7}$ and $\mathbf{1 4}$ in mouse livers by LC-MS/MS, mouse liver tissues were homogenized in $4 \times$ (w:v) of acetonitrile/ $\mathrm{H}_{2} \mathrm{O}(1: 1)$ using a bead ruptor. Liver homogenates $(25 \mu \mathrm{L})$ were subjected to protein precipitation with $150 \mu \mathrm{L}$ of acetonitrile containing $0.2 \mu \mathrm{M}$ of CHK-12289 (in-house GO inhibitor, MW $=289.23$ ) as the internal standard (IS). The samples were then centrifuged at $4,300 \times \mathrm{g}$ for $20 \mathrm{~min}$ at $4{ }^{\circ} \mathrm{C}$, and $100 \mu \mathrm{L}$ of the supernatants were transferred to a deep well 96 well plate containing equal volume of LC-MS grade $\mathrm{H}_{2} \mathrm{O}$. The plate was mixed for $5 \mathrm{~min}$ at $23{ }^{\circ} \mathrm{C}$, and $5 \mu \mathrm{L}$ of the sample was injected into UPLC. Chromatographic separation was achieved using Agilent Zorbax SB-C8 RRHD $2.1 \times 50 \mathrm{~mm}$ column, with $0.1 \%$ acetic acid in water (mobile phase A) and $0.1 \%$ acetic acid in acetonitrile (mobile phase $B$ ) run at $0.4 \mathrm{~mL} / \mathrm{min}$ as per the following gradient: $5 \%$ for $0.5 \mathrm{~min}$, 5-90\% B over $0.5 \mathrm{~min}, 95 \% \mathrm{~B}$ for $1 \mathrm{~min}, 95-5 \%$ B over $0.1 \mathrm{~min}$, and 5\% B for $1.40 \mathrm{~min}$. Total run time was $3.5 \mathrm{~min}$. The samples were analyzed using Sciex QTRAP 5500 linear ion trap mass spectrometer operated in multiple reaction monitoring (MRM) mode under negative ionization. The MRM transitions were $\mathrm{m} / \mathrm{z} 653.86$ to $\mathrm{m} / \mathrm{z} 610.0$ for Compound 7, m/z 731.93 to $\mathrm{m} / \mathrm{z} 577.10$ for Compound 14, and m/z 287.88 to m/z 215.9 for the IS. 


\section{PD Analysis}

To quantify glycolate levels in mouse plasma by LC-MS/MS, plasma samples $(25 \mu \mathrm{L})$ were subjected to protein precipitation with $150 \mu \mathrm{L}$ of acetonitrile containing $100 \mu \mathrm{M}$ of ${ }^{13} \mathrm{C}_{2}$-glycolate as the internal standard (IS), followed by centrifugation at $4,300 \times \mathrm{g}$ for $20 \mathrm{~min}$ at $4{ }^{\circ} \mathrm{C}$. Supernatants $(120 \mu \mathrm{L})$ were transferred to a deep well 96 well plate containing $50 \mu \mathrm{L}$ of LC-MS grade $\mathrm{H}_{2} \mathrm{O}$. The plate was mixed for $5 \mathrm{~min}$ at $23^{\circ} \mathrm{C}$, and $5 \mu \mathrm{L}$ of the sample was injected into UPLC. Chromatographic separation was achieved using Atlantis HILIC Silica $3 \mu \mathrm{m}, 2.1 \times 50 \mathrm{~mm}$ column, with mobile phase $A$ ( $10 \mathrm{mM}$ ammonium acetate in water) and mobile phase $B(10 \mathrm{mM}$ ammonium acetate in $90 \%$ acetonitrile and $10 \%$ water), run at $0.75 \mathrm{~mL} / \mathrm{min}$ as per the following gradient $100 \% \mathrm{~B}$ for $0.5 \mathrm{~min}, 100-30 \%$ B over 1 $\mathrm{min}, 30 \%$ B for $0.5 \mathrm{~min}, 30-100 \%$ over $0.1 \mathrm{~min}$, and then $100 \%$ B for $3.4 \mathrm{~min}$. Total run time was $5.5 \mathrm{~min}$. The samples were analyzed using Sciex QTRAP 5500 linear ion trap mass spectrometer operated in multiple reaction monitoring (MRM) mode under negative ionization. The MRM transitions were $\mathrm{m} / \mathrm{z} 74.877$ to $\mathrm{m} / \mathrm{z} 47.1$ for glycolate and $\mathrm{m} / \mathrm{z}$ 76.863 to $\mathrm{m} / \mathrm{z} 48.1$ for ${ }^{13} \mathrm{C}_{2}$-glycolate (IS).

\section{References:}

1. Murray, M. S., Holmes, R. P., and Lowther, W. T. (2008) Active site and loop 4 movements within human glycolate oxidase: implications for substrate specificity and drug design. Biochemistry 47, 2439-2449

2. Rai, G., Brimacombe, K. R., Mott, B. T., Urban, D. J., Hu, X., Yang, S. M., Lee, T. D., Cheff, D. M., Kouznetsova, J., Benavides, G. A., Pohida, K., Kuenstner, E. J., Luci, D. K., Lukacs, C. M., Davies, D. R., Dranow, D. M., Zhu, H., Sulikowski, G., Moore, W. J., Stott, G. M., Flint, A. J., Hall, M. D., Darley-Usmar, V. M., Neckers, L. M., Dang, C. V., Waterson, A. G., Simeonov, A., Jadhav, A., and Maloney, D. J. (2017) Discovery and Optimization of Potent, Cell-Active Pyrazole-Based Inhibitors of Lactate Dehydrogenase (LDH). J Med Chem 60, 91849204

3. Emsley, P., Lohkamp, B., Scott, W. G., and Cowtan, K. (2010) Features and development of Coot. Acta Crystallogr D Biol Crystallogr 66, 486-501

4. Winn, M. D., Murshudov, G. N., and Papiz, M. Z. (2003) Macromolecular TLS refinement in REFMAC at moderate resolutions. Methods Enzymol 374, 300-321

5. Chen, V. B., Arendall, W. B., 3rd, Headd, J. J., Keedy, D. A., Immormino, R. M., Kapral, G. J., Murray, L. W., Richardson, J. S., and Richardson, D. C. (2010) MolProbity: all-atom structure validation for macromolecular crystallography. Acta Crystallogr D Biol Crystallogr 66, 12-21

6. Laskowski, R., MacArthur, M., Moss, D., and Thornton, J. (1993) PROCHECK - a program to check the stereochemical quality of protein structures. J App Cryst 26, 283-291

7. Salido, E. C., Li, X. M., Lu, Y., Wang, X., Santana, A., Roy-Chowdhury, N., Torres, A., Shapiro, L. J., and RoyChowdhury, J. (2006) Alanine-glyoxylate aminotransferase-deficient mice, a model for primary hyperoxaluria that responds to adenoviral gene transfer. Proceedings of the National Academy of Sciences of the United States of America, 103, 18249-18254.

8. Fargue, S., Milliner, D. S., Knight, J., Olson, J. B., Lowther, W. T., and Holmes, R. P. (2018). Hydroxyproline Metabolism and Oxalate Synthesis in Primary Hyperoxaluria. Journal of the American Society of Nephrology, 29, 1615-1623. 
JD0211-063-1HNMR

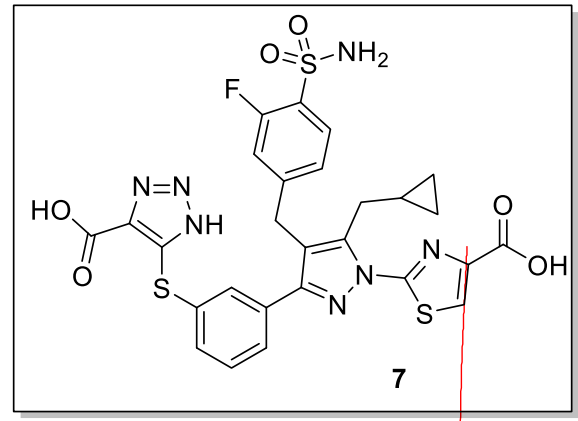

water DMSO

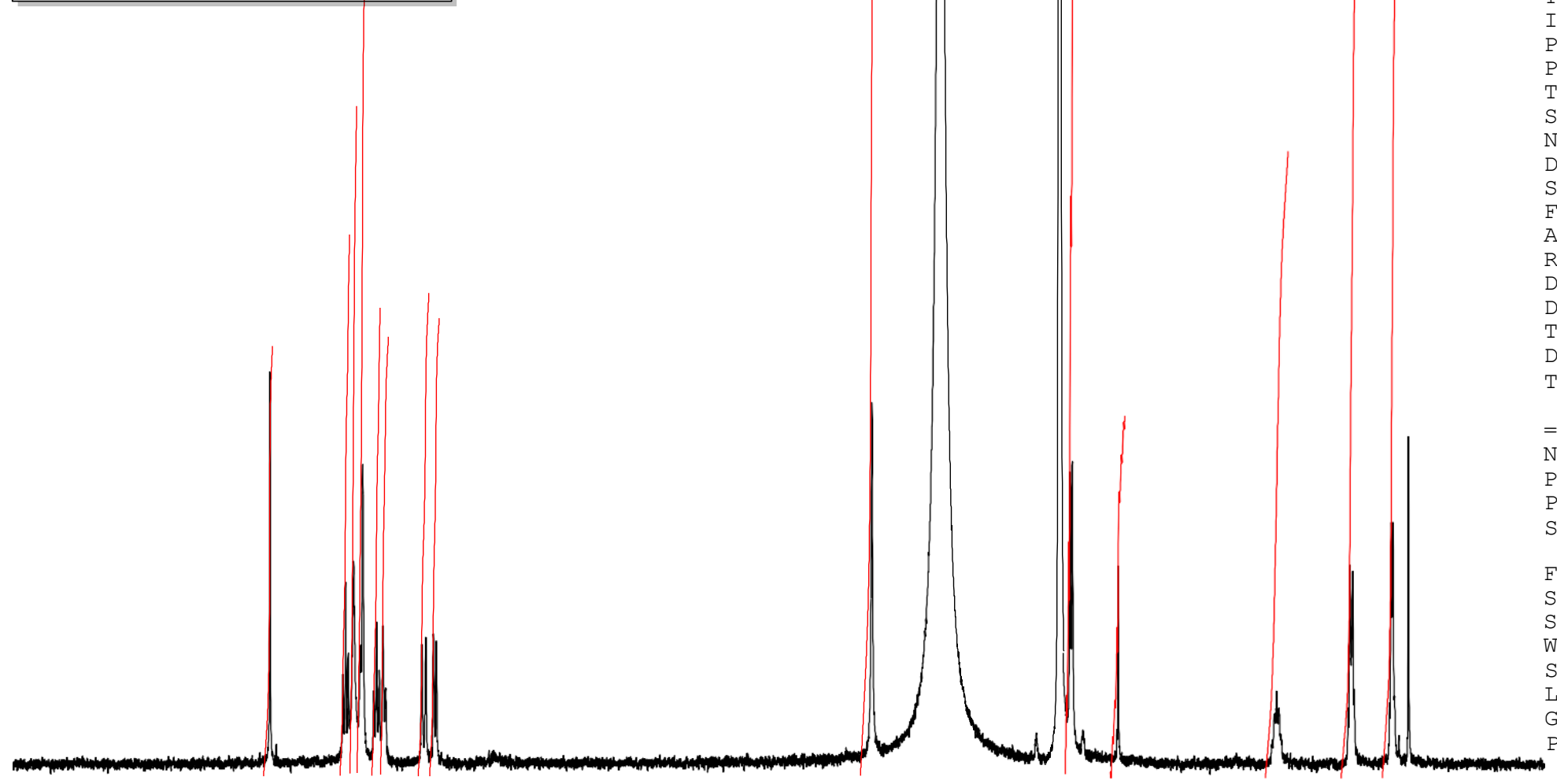

Current Data Parameters

NAME JD0211-063-1HNMR

EXPNO UD $11-063-11 \mathrm{~N}$

PROCNO

2 - Acquisition Parameters

Date_ 20190725

$\begin{array}{lr}\text { Time } & 9.37\end{array}$

ROBHD $5 \mathrm{~mm}$ Multinucl

PULPROG zg30

65536

SOLVENT

NS

DS

FIDRES

$A Q$

RG

$8250.825 \mathrm{~Hz}$ $0.125898 \mathrm{~Hz}$ 3.9715316 sec 1149.4

60.600 usec 86.57 usec $292.6 \mathrm{~K}$

$====-$ CHANNET f 1 $\mathrm{NUC1}$ $292.6 \mathrm{~K}$

PL1

$1 \mathrm{H}$

SFO1

$0.00 \mathrm{~dB}$

- Processing parameters SI 32768

SF $\quad 400.1300112 \mathrm{MHz}$

WDW

SB

LB

$\mathrm{EM}$
0
$0.30 \mathrm{~Hz}$

$0.30 \mathrm{~Hz}$

1.00

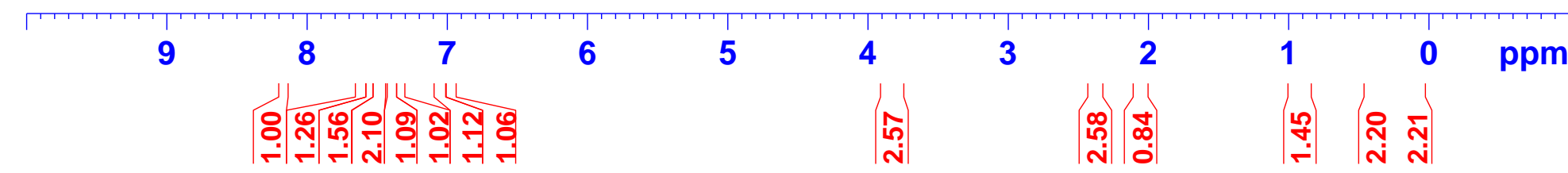


JD0211-046-1HNMR
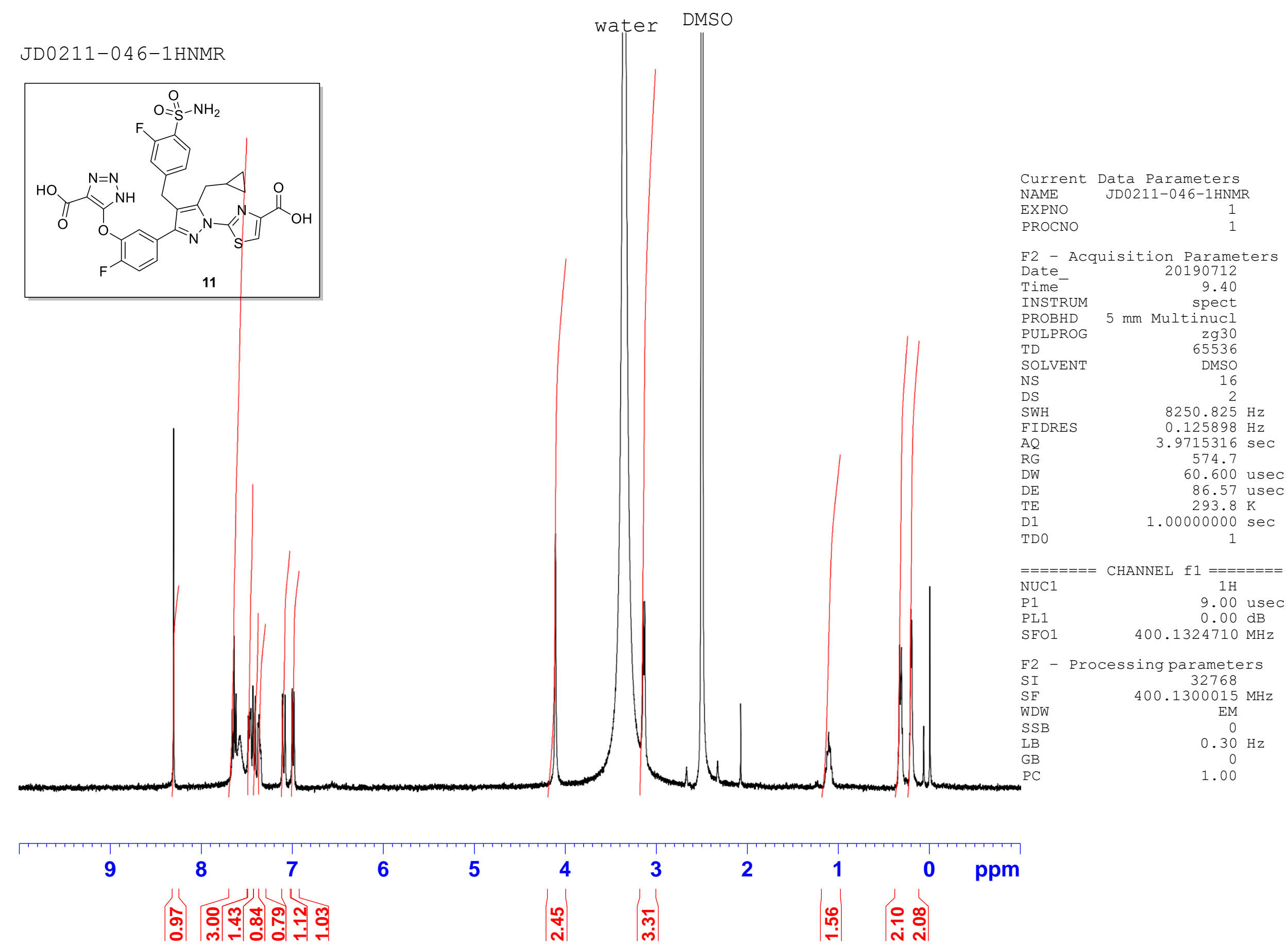
JD0211-075-1HNMR
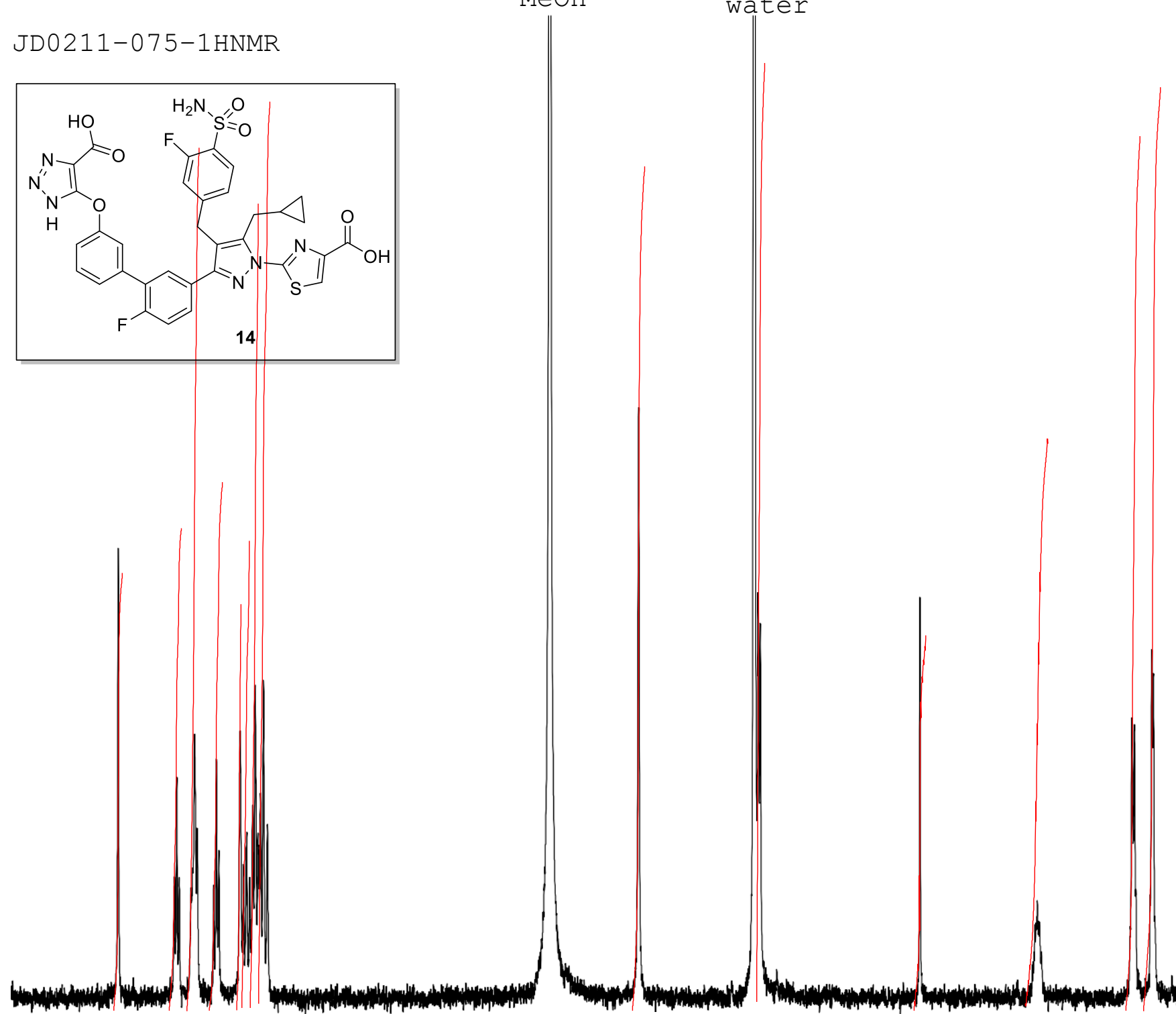

Current Data Parameters NAME JD0211-075-1HNMR

EXPNO JD0211-075-1HNMR

PROCNO 1

F2 - Acquisition Parameters

Date 20190801

Time15.01

TRUM

PROBHD

$5 \mathrm{~mm}$ Multinucl

$$
\mathrm{TD}
$$

SOLVENT

NS

SWH

FIDRES

$\mathrm{AQ}$

RG

DW

$\mathrm{TE}$

TDO

zg30

65536

4

$8250.825 \mathrm{~Hz}$ $0.125898 \mathrm{~Hz}$ $3.9715316 \mathrm{sec}$ 1149.4

60.600 usec 86.57 usec $294.5 \mathrm{~K}$

NUC1

$1.00000000 \mathrm{sec}$

CHANNEL

PL1

$1 \mathrm{H}$

SFO1

F2 - Processing parameters SI 32768

SF $\quad 400.1300112 \mathrm{MHz}$

WDW

SSB

$\mathrm{LB}$

EM
0
$0.30 \mathrm{~Hz}$
0

(1)

1.00

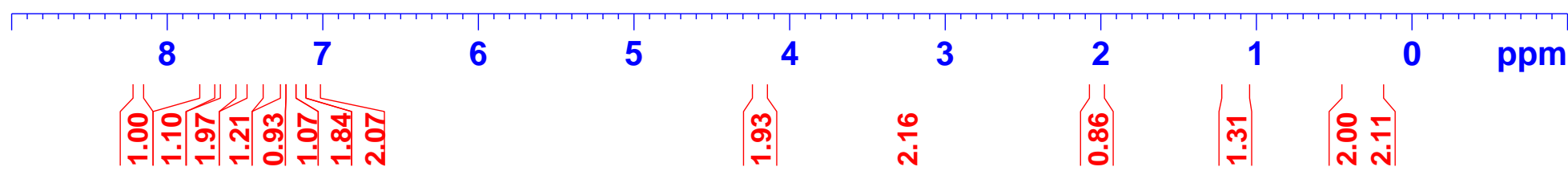


JD0211-087-1HNMR
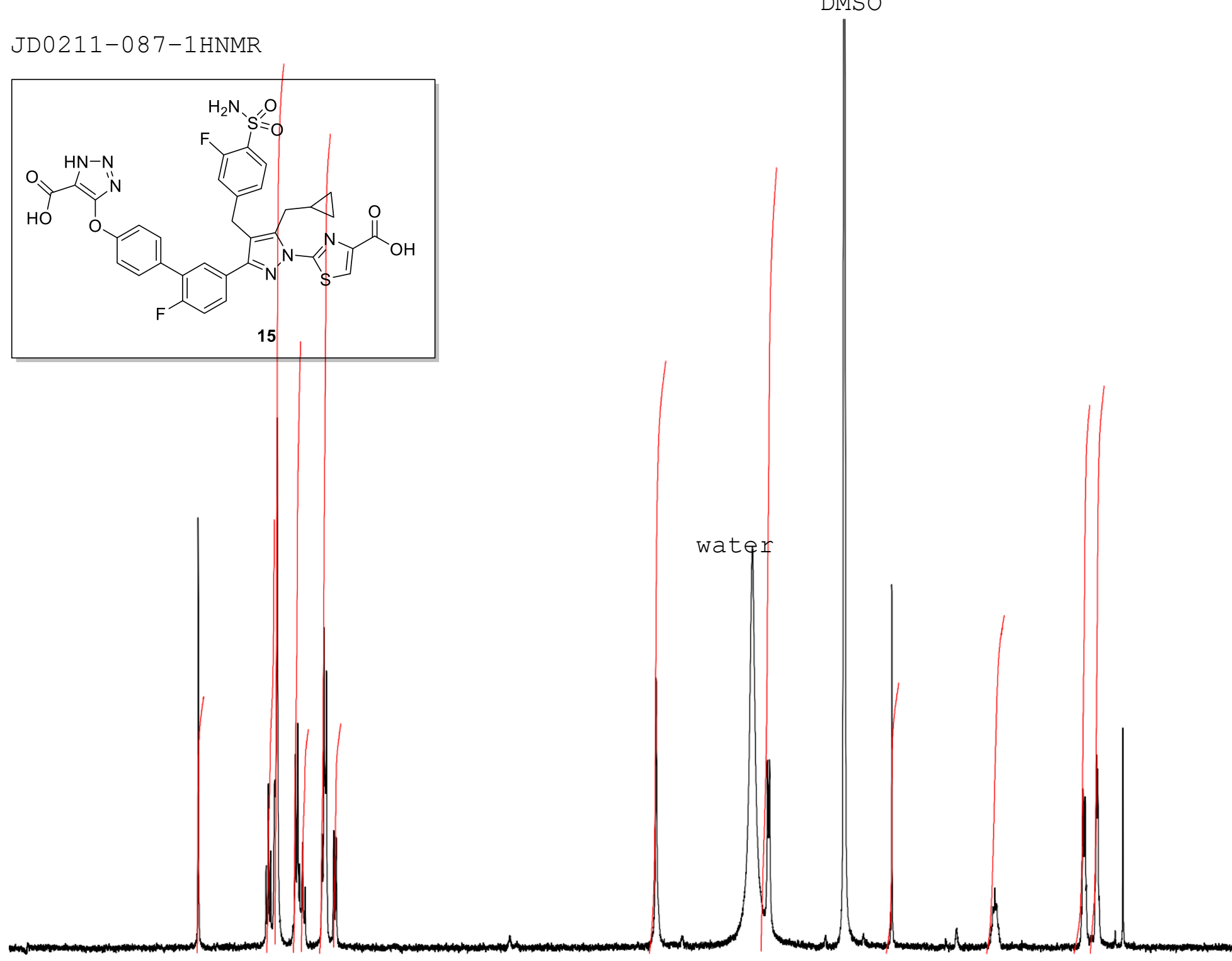

Current Data Parameters NAME JD0211-087-1HNMR EXPNO JD0211-087-1HNMR RROCNO

F2 - Acquisition Parameters

Date 20190814

$\begin{array}{lr}\text { Time } & 16.28 \\ \text { TNSTRUM } & \text { spect }\end{array}$

ROBHD $5 \mathrm{~mm}$ Multinucl.

PULPROG zg30

TOIVNT

S

SWH

$A Q$

RG

DW

DE

1

TDO

$8250.825 \mathrm{~Hz}$

$0.125898 \mathrm{~Hz}$

$3.9715316 \mathrm{sec}$

574.7

60.600 usec

86.57 usec

$297.0 \mathrm{~K}$

raren 1

$=====$ CHANNEL f $1========$ $\mathrm{NUC1}$

P1

PL1

$1 \mathrm{H}$

$\mathrm{SFO} 1$

$0.00 \mathrm{~dB}$

- Processing parameters

SI 32768

SF $\quad 400.1300015 \mathrm{MHz}$

WDW

SSB

LB

$\mathrm{EM}$
0
$0.30 \mathrm{~Hz}$

0.30
0

1.00

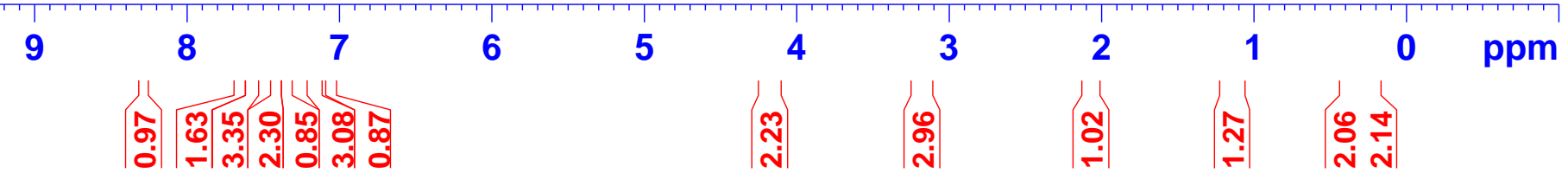


JD0211-083-1HNMR
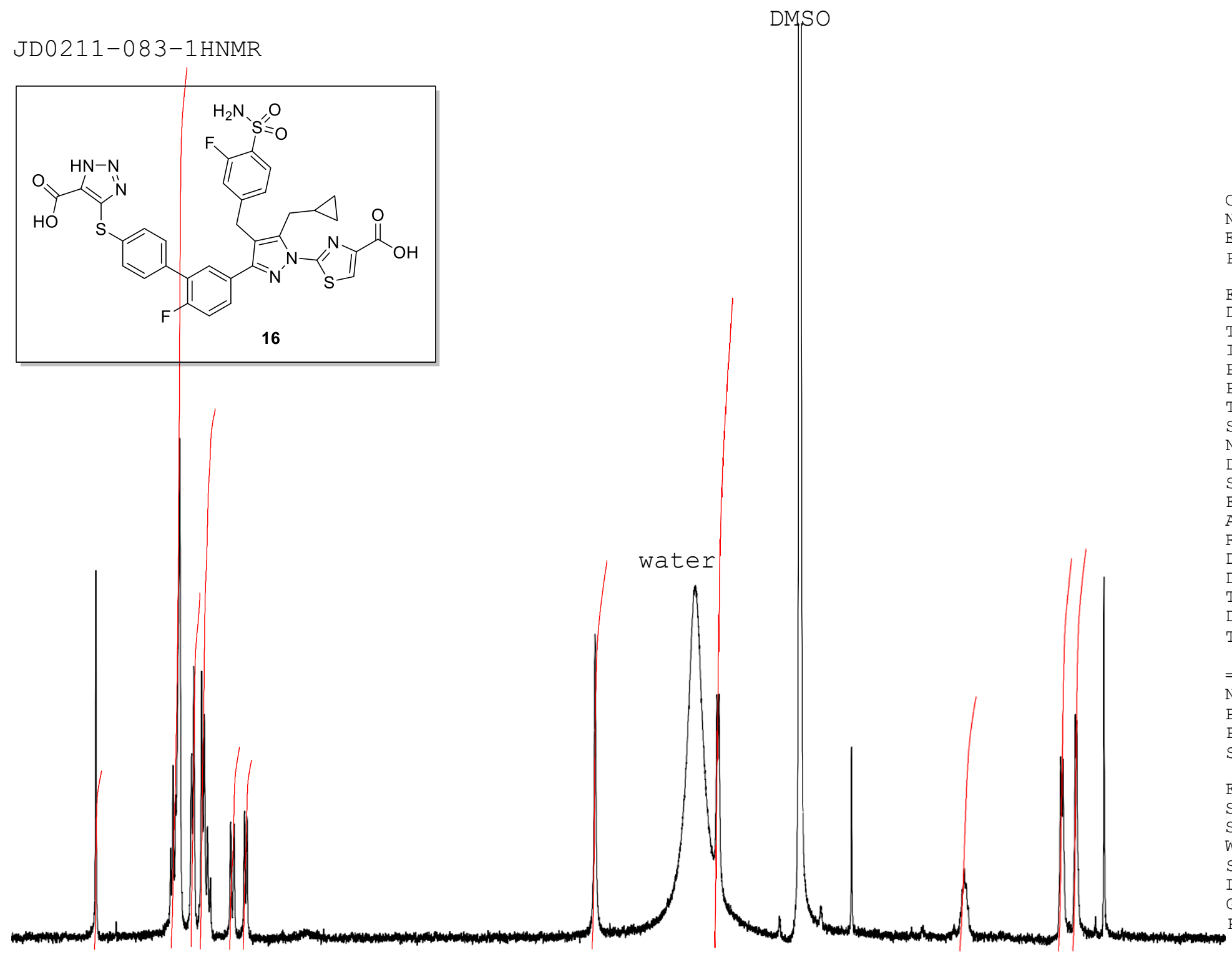

Current Data Parameters NAME JD0211-083-1HNMR PROCNO

2 - Acquisition Parameters

Dater 20190808

$\begin{array}{lr}\text { Time } & 10.13 \\ \text { TNSTRUM } & \text { spect }\end{array}$

PROBHD $5 \mathrm{~mm}$ Multinucl.

PULPROG zg30

SOLVENT

SOL
NS

DS

SWH
FIDRES

AQ

RG

$\mathrm{DW}$

DE

D1

TDO

65536

DMSO

$8250.825 \mathrm{~Hz}$

$0.125898 \mathrm{~Hz}$

$3.9715316 \mathrm{sec}$

1149.4

60.600 usec

86.57 usec

$293.8 \mathrm{~K}$

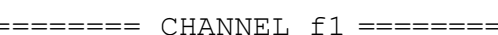

NUC1

$1.00000000 \mathrm{sec}$

PL1

$1 \mathrm{H}$
9.00 usec

$\mathrm{SFO} 1$

$0.00 \mathrm{~dB}$

F2 - Processing parameters SI 32768

SF $\quad 400.1300013 \mathrm{MHz}$

WDW

SSB

GB

EM

$0.30 \mathrm{~Hz}$

0

1.00

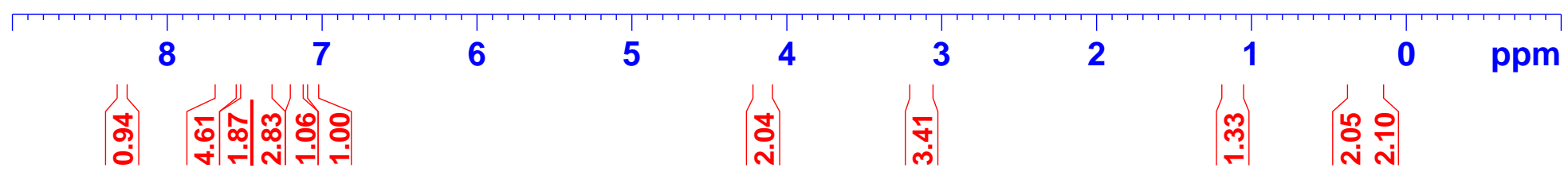


JD0211-085-1HNMR

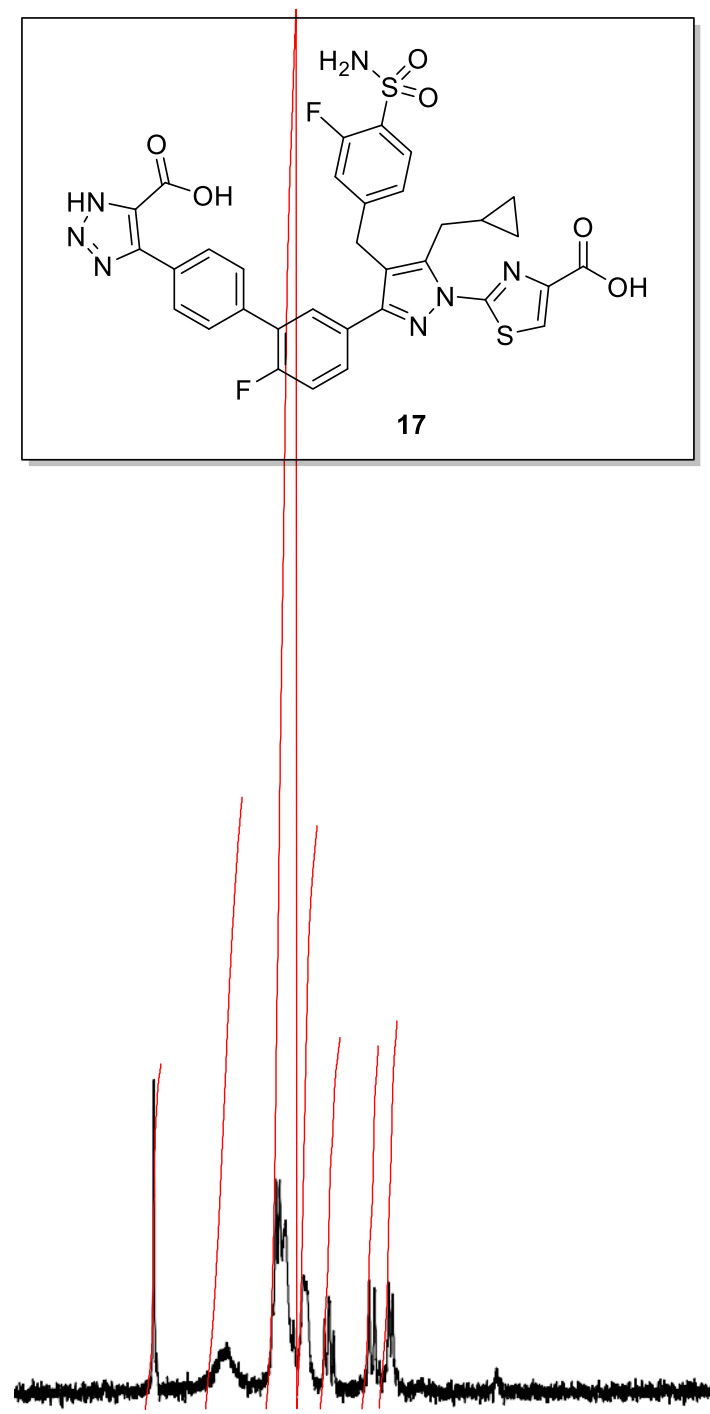

water

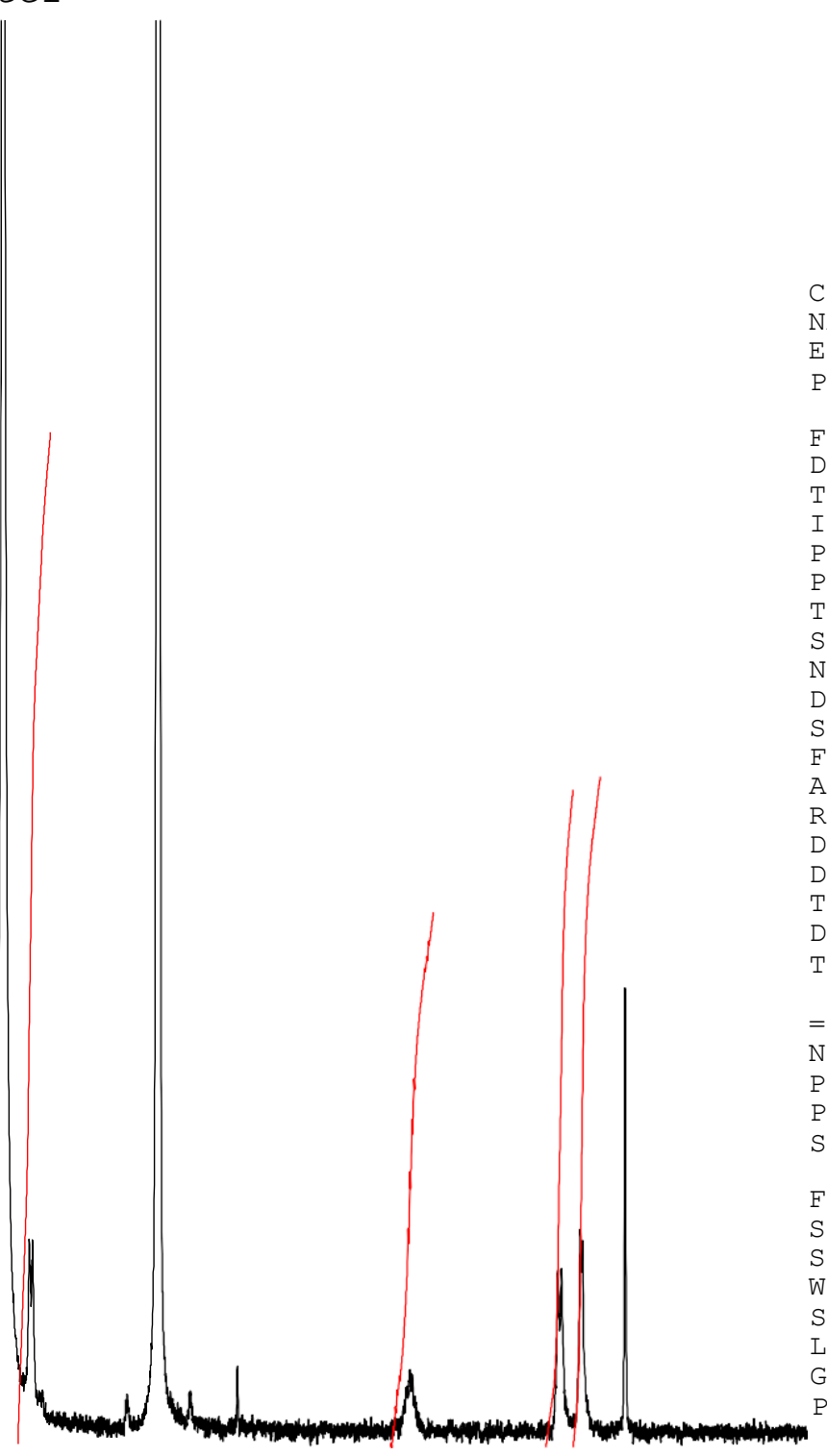

Current Data Parameters NAME JD0211-085-1HNMR TXPNO JD0211-085-1HNMR ROCNO

2 - Acquisition Parameters

Dater 20190808

$\begin{array}{lr}\text { Time- } & 10.23 \\ & \end{array}$

ROBHD $5 \mathrm{~mm}$ Multinucl

PULPROG zg30

$\mathrm{zg} 30$
65536

SOLVENT

NS

DS

FIDRES

AQ

RG

DW

$\mathrm{DE}$

D1

16
2
8250.825

$8250.825 \mathrm{~Hz}$

$0.125898 \mathrm{~Hz}$

$3.9715316 \mathrm{sec}$

1625.5

60.600 usec

86.57 usec

TDO

$1.00000000 \mathrm{se}$

$\begin{array}{lc}=======\text { CHANNEL } \mathrm{f} 1======= \\ \text { NUC1 } & 1 \mathrm{H} \\ \text { P1 } & 9.00 \text { useC } \\ \text { PL1 } & 0.00 \mathrm{~dB} \\ \text { SFO1 } & \end{array}$

SFO1 $400.1324710 \mathrm{MHz}$

2 - Processing parameters SI 32768

SF $\quad 400.1300112 \mathrm{MHz}$

WDW

$\mathrm{SB}$

LB

$\mathrm{GB}$
$\mathrm{PC}$

EM
0
$0.30 \mathrm{~Hz}$
0
1.00

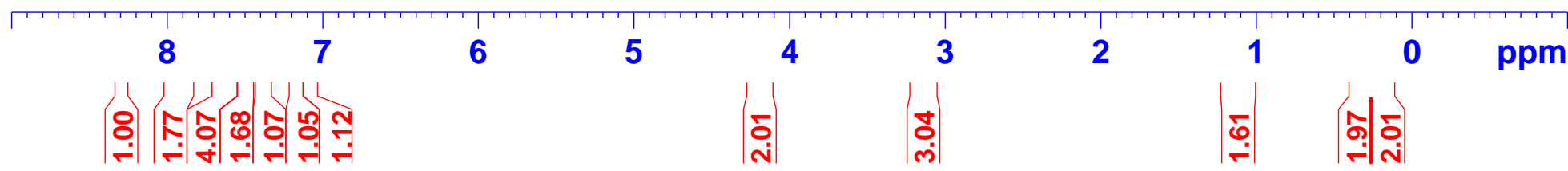

